\title{
Soil measurements during HAPEX-Sahel intensive observation period
}

\author{
R.H. Cuenca ${ }^{a}, *$, J. Brouwer ${ }^{b, c}$, A. Chanzy ${ }^{d}$, P. Droogers ${ }^{e}$, S. Galle ${ }^{f}$, \\ S.R. Gaze ${ }^{g}$, M. Sicot ${ }^{h}$, H. Stricker ${ }^{\mathrm{e}}$, R. Angulo-Jaramillo ${ }^{\mathrm{i}}$, S.A. Boyle ${ }^{\mathrm{g}}$, \\ J. Bromley ${ }^{g}$, A.G. Chebhouni ${ }^{\mathrm{j}}$, J.D. Cooper ${ }^{\mathrm{g}}$, A.J. Dixon ${ }^{\mathrm{g}}$, J.-C. Fies ${ }^{\mathrm{d}}$, \\ M. Gandah', J.-C. Gaudu ${ }^{\text {d, L. Laguerre', J. Lecocq }}{ }^{i}$, M. Soet ${ }^{\mathrm{e}}$, \\ H.J. Steward ${ }^{\mathrm{g}}$, J.-P. Vandervaere ${ }^{\mathrm{i}}$, M. Vauclin ${ }^{\mathrm{i}}$ \\ ${ }^{2}$ Department of Bioresource Engineering, Gilmore Hall, Oregon State University, Corvallis, \\ OR 97331-3906, USA \\ 'ICRISAT-ST, BP 12404, Niamey, Niger \\ 'Department of Soil Science and Geology, Agricultural University Wageningen, P.O. Box 37, \\ 6700 AA Wageningen, Netherlands \\ 'Institut National de Recherches Agronomiques, BP 91, 84143 Montfavet Cedex, France \\ 'Department of Water Resources, Agricultural University of Wageningen, II Nieuwe Kanaal, \\ 6709 PA Wageningen, Netherlands \\ 'ORSTOM, BP 11416, Niamey, Niger \\ 'Institute of Hydrology, Wallingford OXIO 8BB, UK \\ hInstitut des Radio-Isotopes, BP 10727, Niamey, Niger \\ 'Laboratoire d'Etude des Transferts en Hydrologie et Environnement, (CNRS-15I2, UJF, INGP), BP 53, \\ 38041 Grenoble Cedex 9. France \\ jJet Propulsion Laboratory, Mail Stop 300-233, California Institute of Technology, 4800 Oak Grove Dr., \\ Pasadena, CA 91109-8099, USA \\ ${ }^{\mathrm{k}}$ Institut National de Recherches Agronomiques - Niger, Niamey, Niger \\ 'Laboratorie d'Etude et de Recherche en Télédétection Spatial (CNES), BPI 2801, 18 Avenue Edouard Belin, \\ 31055 Toulouse Cedex, France
}

\begin{abstract}
This article describes measurements made at each site and for each vegetation cover as part of the soils program for the HAPEX-Sahel regional scale experiment. The measurements were based on an initial sampling scheme and included profile soil water content, surface soil water content, soil water potential, infiltration rates, additional measurements on core samples, and grain size analysis. The measurements were used to categorize the state of the surface and profile soil water regimes during the experiment and to derive functional relationships for the soil water characteristic curve,
\end{abstract}

\footnotetext{
* Corresponding author.
} 
unsaturated hydraulic conductivity function, and infiltration function. Sample results for different supersites and different vegetation covers are presented showing soil water profiles and total soil water storage on days corresponding to the experimental 'Golden Days'. Sample results are also presented for spatial and temporal distribution of surface moisture content and infiltration tests. The results demonstrate that the major experimental objective of monitoring the supersites during the most rapid vegetative growth stage with the largest change of the surface energy balance following the rainy season was very nearly achieved. Separation of the effects of probable root activity and drainage of the soil profile is possible. The potential for localized advection between the bare soil and vegetation strips of the tiger bush sites is demonstrated.

\section{Introduction}

\subsection{The HAPEX-Sahel experiment}

The HAPEX (Hydrologic Atmospheric Pilot EXperiment) Sahel (referring to the climatic region bordering the southern Sahara from Senegal to Somalia) experiment was one in a continuing series of regional scale experiments which bring together teams working in the areas of hydrology, ecology, soil science, biological science, atmospheric science, and remote sensing. Other experiments in this series include HAPEX-MOBILHY (MOdélisation du BILan HYdrique) conducted in France in 1986 (André et al., 1988), FIFE (First ISLSCP (International Satellite Land Surface Climatology Project) Field Experiment) conducted in the United States in 1987 (Sellers et al., 1992), EFEDA (ECHIVAL (European International Project on Climate and Hydrological Interactions between Vegetation, Atmosphere and Land Surfaces) Field Experiment in a Desertification-threatened Area) conducted in Spain in 1991 (Bolle et al., 1993), and the BOREAS (BOReal Ecosystem-Atmosphere Study) project conducted in Canada in 1994 (Sellers et al., 1995). The intensive observation period (IOP) of HAPEX-Sahel was from 15 August until 9 October, 1992. Planning for this experiment and establishment of a Coordinating Committee for various components started in 1989.

The overall objective of these experiments is to improve understanding of the physical and biological processes of the Earth's ecosystem, hydrologic system, and atmospheric system. Improved understanding of these processes will allow for more accurate evaluation of humankind's impact on the planet and better projections of future climates and their effects. The experiments have been operated in different ecosystems and climates (HAPEX-MOBILHY - temperate and humid; EFEDA - temperate and arid; HAPEXSahel - tropical and arid; BOREAS - temperate boreal forest) to improve our understanding of physical and biological processes over different land surface types which cover large portions of the Earth's land mass.

The experimental area of HAPEX-Sahel comprised an approximately $100 \mathrm{~km}$ by $100 \mathrm{~km}$ grid square between 13 and $14^{\circ} \mathrm{N}$ latitude and 2 and $3^{\circ} \mathrm{E}$ longitude. It included Niamey, capital of the Republic of Niger, and part of the Niger River. The experimental terrain was 
made up of the remains of the Continental Terminal which is dissected by sand-filled valleys which are in turn separated by plateaux. The major vegetation types are arable crops (predominantly millet), fallow savanna, and a sparse dry-land forest known locally as tiger bush. The tiger bush is confined to the laterite plateaux. Vegetation density decreases in a northerly direction over the region in response to the long-term rainfall gradient. A general description of the experiment including experimental approach, spatial and temporal sampling strategy, areal and climatic descriptions, instrumentation, and samples of data collected is given in Goutorbe et al. (1994). This article will focus on description of measurements of soil physical properties and soil water monitoring during the HAPEX-Sahel intensive observation period (IOP). The objective of this paper is to serve as a reference for future work dealing with the soils data from HAPEX-Sahel.

\subsection{Soils component of regional experiments}

Soil water conditions are basic input data for hydrologic balance, atmospheric, and climatic modeling studies. The status of the soil water profile is generally required for model initialization, calibration, and verification. Soil water affects all phases of the continental water balance since infiltration and evapotranspiration processes vary as a function of the degree of soil saturation (Taylor and Ashcroft, 1972; Hillel, 1982). Recognition of the importance of soil moisture conditions to general circulation model (GCM) initialization and verification necessitated regular monitoring of profile soil water within HAPEX-MOBILHY, the first large scale experiment of this type (André et al., 1988). The seasonal variation of soil water content was clearly demonstrated by almost 2 years of profile soil water data taken at 12 sites over the $100 \mathrm{~km}$ by $100 \mathrm{~km}$ HAPEX-MOBILHY grid (Goutorbe et al., 1989). In this case, the rewetting pattern from winter precipitation was clearly shown to depend on soil texture.

The hydrologic balance computed using the comparatively slow changes in soil water status has been used to verify cumulative flux measurements made by surface instruments operating over shorter time periods (Cuenca, 1988; Goutorbe et al., 1989; Cuenca and Noilhan, 1991). Measurements of changes in soil water content at multiple locations within the same measurement site can give insight into the expected spatial variability of fluxes which are integrated by surface instrumentation. The variation of soil water properties can be used to estimate reasonable ranges of expected variation of a hydrologic balance on a regional scale for similar soil conditions. Up-scaling from point to areal or regional estimates of the hydrologic balance can be aided by measurements of soil properties for soils of similar length scales (Nielsen et al., 1973; Simmons et al., 1979; Hopmans and Stricker, 1989; Warrick, 1990; Clausnitzer et al., 1992).

The soils component of HAPEX-Sahel was integrated into the project from the initial stages of planning in 1989. A protocol for the soil measurement program was developed in joint meetings with representatives of all teams scheduled to make such measurements. This protocol included an initial soil water sampling strategy for each site, selection of long-term and IOP monitoring sites based on the initial sampling, and the protocol for soil water content and potential measurements for each vegetation cover. Details for each supersite and vegetation cover are described in Section 2. (A supersite is defined as an 
experimental area comprised of at least three different vegetation covers each monitored using associated flux measuring equipment.) The high degree of uniformity of soil water and soil property measurements carried out at each site was due to the coordination and communication between the various soil monitoring teams. In this sense, HAPEX-Sahel can be used as a model for large scale, multi-disciplinary experiments.

Table 1

Information on soil measurement program for Central East Supersite on all vegetation subsites (Fallow, Millet, Millet on Sandy Skirt, Tiger Bush) except as noted

Initial sampling

Gravimetric sampling by auger to $1 \mathrm{~m}$ depth on 6 by 6 grid with $50 \mathrm{~m}$ spacing between sample points - beginning, middle and end of rainy season

Profile soil water content

Instrument

Solo Model 25 Neutron Probe

Number of access tubes 11 (based on original $50 \mathrm{~m}$ by $50 \mathrm{~m}$ grid)

Depths monitored

Frequency

Start at $10 \mathrm{~cm}$, every $10 \mathrm{~cm}$ to $1.0 \mathrm{~m}$, every $20 \mathrm{~cm}$ from 1.0 to $3.6 \mathrm{~m}$

IOP and rainy season -3 times week ${ }^{-1}$

End rainy season to December - 1 time week

December to start rainy season - 1 time week $^{-1}$

Procedure

1 reading per depth layer, $20 \mathrm{~s}$ count time

Surface soil water content

Instrument

Trase TDR (Tiger Bush excluded)

Sample points

21 on 3 by 7 grid with $50 \mathrm{~m}$ spacing

Depths monitored

0 to $15 \mathrm{~cm}$ integrated

Frequency

1 to 7 days in Millet and Fallow. In conjunction with NASA C-130 and PORTOS overflights on Millet-Sandy Skirt

Procedure

1 to 3 samples per point

Instrument

Gravimetric sampling (Including Fallow INRA, excluding Tiger Bush)

Sample points 15

Depths monitored

0 to $0.5,0.5$ to 2,2 to 5,5 to 10,10 to $15 \mathrm{~cm}$

Frequency

In conjunction with NASA C-130 and PORTOS overflights on Millet-Sandy Skirt

Soil water potential

Instrument

Tensimeter hypodermic tensiometer

Sample points

Depths monitored

Same as neutron probe

200 and $250 \mathrm{~cm}$

Frequency

Instrument

Sample points

Same as for Profile soil water

Hg tensiometer

Depths monitored

$5,10,40,65,90,115,140,190,220$, and $240 \mathrm{~cm}$ ( 220 maximum in Millet)

Infiltration tests

Instrument

Sample points

Tensions

Procedure

Tension infiltrometers - 25, two 8 and $4.85 \mathrm{~cm}$ diameter

3 sites with 4 infiltrometers at each site

$11.5,9,6,3,1$, and $0 \mathrm{~cm}$

Measured crust and graded sand base (no graded sand base for Millet)

Additional data collection

$100 \mathrm{~cm}^{3}$ surface density samples, 4 samples per access tube, 3 sample dates during rainy season (no additional sampling for Millet on Sandy Skirt and Tiger Bush) 
Table 2

Information on soil measurement program for Central West Supersite on all vegetation subsites (Bush-Grassland, Grassland, Degraded Bush) except as noted

Initial sampling

None

Profile soil water content

Instrument

Number of access tubes

CPN Hydroprobe Model 503 - Neutron Probe

Depths monitored

Frequency

Procedure

12 in Bush Grassland, 14 in Degraded Bush, 4 in Grassland, 10 in Millet

Instrument

Sample points

Depths monitored $15,25,35,45,60,75,95,115,135,155$, and $170 \mathrm{~cm}$

IOP - every other day

1 reading per depth layer, $16 \mathrm{~s}$ count time

Tektronix Cable Tester, Easy Test TDR

4 in Bush Grassland, 4 in Degraded Bush, 2 in Grassland, 4 in Millet

5 and $10 \mathrm{~cm}$ (sensors horizontal) and 20 to 30 and 40 to $50 \mathrm{~cm}$ (sensors vertical) ( 3 replications at each depth per standard plot)

Frequency

IOP - every other day

Surface soil water content

Instrument

Sample points

\section{Easy Test TDR}

10 in Bush Grassland on transect, 41 in Degraded Bush on 5 parallel transects, 32 in Millet irregularly placed

Depths monitored

5 and $10 \mathrm{~cm}$ (sensors horizontal)

Frequency

IOP - every other day

Instrument

Gravimetric Sampling (excluding Millet)

Sample points

10 in Bush Grassland on transect, 41 in Degraded Bush on 5 transects, 27 in

Grassland

Depths monitored

0 to $10 \mathrm{~cm}$

Frequency

In conjunction with NASA C-130 and PORTOS overflights. Dates vary by vegetation cover

Soil water potential

Instrument

Tensimeter hypodermic tensiometer

Sample points

Depths monitored

4 in Bush Grassland, 4 in Degraded Bush, 2 in Grassland, 4 in Millet

$25 \mathrm{~cm}$ and $45 \mathrm{~cm}$ (3 replications)

Frequency

IOP - every other day

Infiltration tests

Instrument

2 matched tension infiltrometers $-18 \mathrm{~cm}$ diameter

Sample points

Tensions

Procedure

3 sites in Bush Grassland, 6 sites in Degraded Bush, 3 sites in Millet (2 infiltrometers per site in each case)

$11.5,9,6,3$, and $0 \mathrm{~cm}$

Measured with and without crust; graded sand base

Additional data collection

$100 \mathrm{~cm}^{3}$ undisturbed soil samples along 1 profile at $10,20,30,37,45$, and $55 \mathrm{~cm}$ depth in Bush Grassland

$100 \mathrm{~cm}^{3}$ undisturbed soil samples, 2 samples per access tube, 1 at $10-15 \mathrm{~cm}$ depth and 1 at $35-40 \mathrm{~cm}$ depth in Bush Grassland

Undisturbed soil samples along one $7 \mathrm{~m}$ long transect, 10 sites on transect, 3 samples per site at $10 \mathrm{~cm}$ depth, 1 sample each of $100 \mathrm{~cm}^{3}, 250 \mathrm{~cm}^{3}$, and $600 \mathrm{~cm}^{3}$ volume in Bush Grassland

Undisturbed soil samples along 1 transect $10 \mathrm{~m}$ long, 10 sample points, 2 samples per point, $1 \mathrm{of} 100 \mathrm{~cm}^{3}$ and 1 of $600 \mathrm{~cm}^{3}$ in Degraded Bush

$100 \mathrm{~cm}^{3}$ undisturbed soil samples, 2 samples per access tube, 1 at $10-15 \mathrm{~cm}$ depth and 1 at $35-40 \mathrm{~cm}$ depth in Millet 


\section{Instrumentation and data collection}

\subsection{Data collection by supersite and vegetation cover}

This section describes in some detail the soils-related measurements made at each supersite and for each vegetation cover within HAPEX-Sahel. The types of measurement are described for the categories of initial sampling, profile soil water content, surface soil

Table 3

Information on soil measurement program for Southern Supersite on all vegetation subsites (Fallow, Millet, Tiger Bush) except as noted

Initial sampling

30 access tubes installed to $2 \mathrm{~m}$ depth on 6 by 5 grid with $50 \mathrm{~m}$ spacing between sample points - beginning, middle and end of rainy season (Tiger Bush excluded)

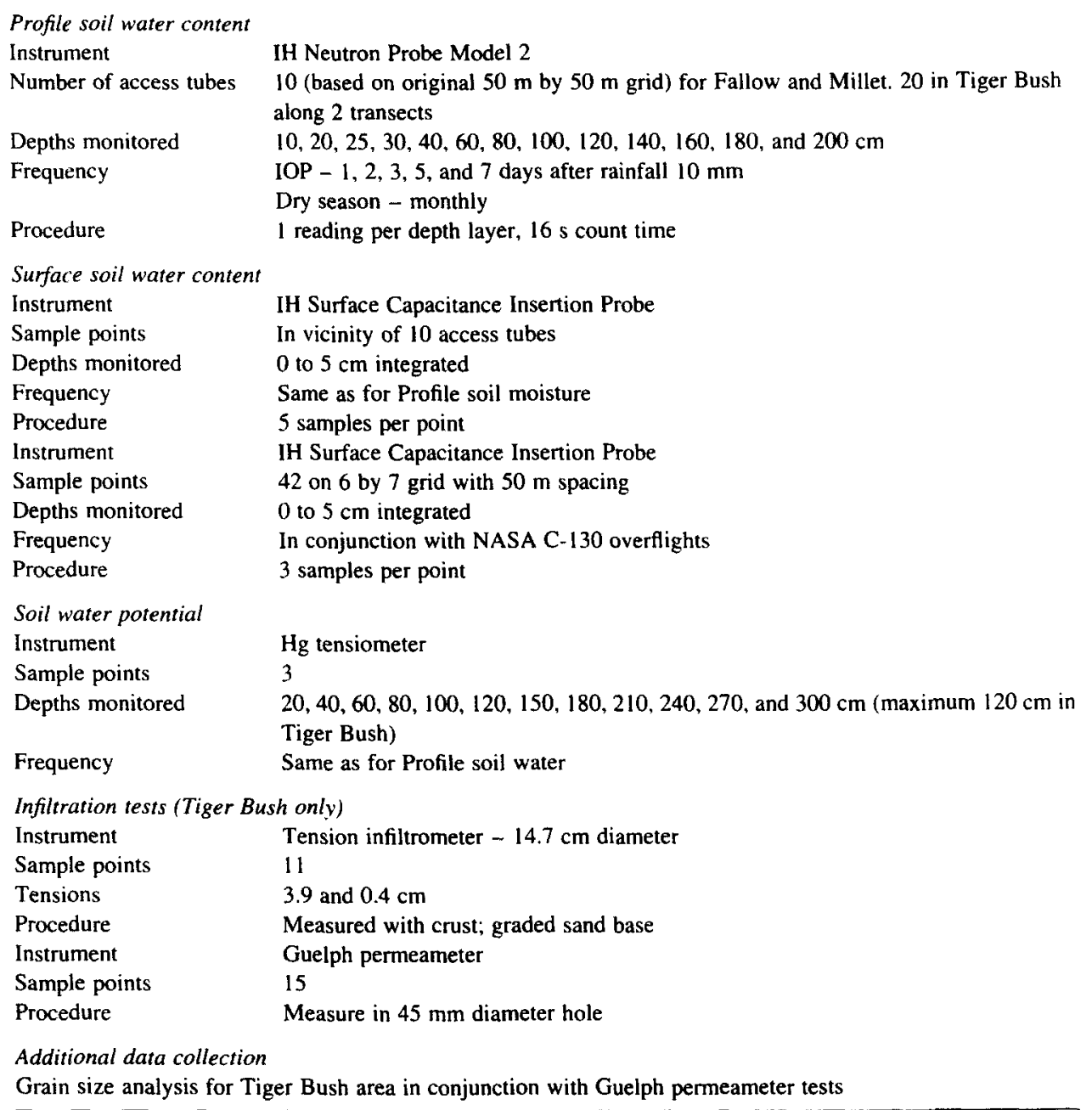


water content, soil water potential, infiltration tests, and additional data collection. This information is indicated in tabular form for each supersite (Tables 1-3).

The general sampling protocol called for initial gravimetric sampling of soil water content to $1 \mathrm{~m}$ depth on a five by six point grid for each vegetation cover with approximately $50 \mathrm{~m}$ spacing between sampling points. The purpose of the initial sampling was two-fold. One reason was to allow for geostatistical analysis of the spatial variability of soil water and eventually soil properties using these initial samples (Vauclin and Vachaud, 1981). The other was to determine representative locations for neutron probe access tubes which would be monitored frequently during the IOP, as well as over a longer time span for some sites. For neutron probe monitoring, the protocol called for ten sites (i.e. ten access tubes) per vegetation cover with measurements starting at $10 \mathrm{~cm}$ depth and continuing every $10 \mathrm{~cm}$ to $1.0 \mathrm{~m}$ depth and every $20 \mathrm{~cm}$ thereafter. Representative locations were chosen to cover the full range of soil water conditions found within each subsite. The monitoring frequency was to be triggered by rainfall events during the IOP - the protocol called for monitoring $1,2,3,5$, and 7 days after rainfall of magnitude greater than $10 \mathrm{~mm}$. During the operational phase of the experiment the protocol was varied dependent upon the number of sites to be monitored in comparison with instruments and technical personnel available.

Measurements of soil water content in the surface layer, on the order of 0 to $20 \mathrm{~cm}$ depth (for which a separate calibration is required for the neutron probe) were made at all sites using either time domain reflectometry (TDR) or a capacitance probe, both of which depend on the large difference in dielectric constant between a dry soil and water (Schmugge and Becker, 1991). These measurements were made in support of soil physical property studies by individual soil teams as well as in support of remote sensing overflights by aircraft carrying microwave instrumentation, i.e. the NASA C-130 and the French ARAT Fokker 27 flying the PORTOS system (Nichols et al., 1993; Goutorbe et al., 1994).

Soil water potential measurements and infiltration measurements were made in support of specific objectives related to determination of soil physical properties and soil water balances. These properties, the definitions of which are essential for simulation models at various scales, include the soil water characteristic curve (relating potential to soil water content), the infiltration function (relating infiltration rate to soil water content and time), and the hydraulic conductivity function (relating hydraulic conductivity to soil water content or potential). Potential measurements were made using water filled tensiometers with either classical mercury $(\mathrm{Hg})$ manometers or monitored by insertion of a hypodermic needle into the tensiometer cap and using a pressure transducer to measure water pressure (Mullins, 1991). Soil water potential measurements were made in the vicinity of neutron probe monitoring tubes, but generally at fewer sites than the neutron probe monitoring.

Valentin and Bresson (1992) demonstrated the effect of surface crusts in tropical soils, building on the classical work in this area by Casenave and Valentin (1989). Control of the infiltration process by crusts, rarely of concern in temperate soils, is an essential element in understanding the redistribution of rainfall throughout the HAPEX-Sahel experimental area. Infiltration measurements were generally made using a tension infiltrometer (Jarvis et al., 1987; Perroux and White, 1988) while some tests were made using the saturated stain method (Boiffin and Monnier, 1985) or the Guelph permeameter (Reynolds and 
Elrick, 1985). Use of the Triple Ring Infiltration Measurement System (TRIMS) required infiltration measurements using infiltrometers with different base radii operated under different tensions (Vauclin and Chopart, 1992). For soils with a stable structure (i.e. negligible swelling or shrinking during the infiltration test), results from the tension infiltrometer systems can be used to infer the functional relationship between hydraulic conductivity and soil water potential (Reynolds and Elrick, 1991; Ankeny et al., 1991; Thony et al., 1991).

Additional data collected included surface density samples, core samples for later laboratory analysis, and grain size analysis. Review of Tables 1-3 indicates an impressive degree of uniformity of measurements made at the various sites and quite satisfactory adherence to the sampling protocol established for this aspect of the experiment.

\subsection{Instrument calibration}

Numerous difficulties were experienced working in the Sahelian environment which affected both equipment and personnel. In certain cases, unusual techniques had to be used for installation and calibration of instruments applied in the soils program. A description of techniques used to calibrate the various instruments follows. Some detail is given in order that this article may be used as a reference for future work dealing with soil data from HAPEX-Sahel.

\subsubsection{Neutron probe}

At the Southern Site, field calibration based on the technique described by Bell (1987) was carried out for a sandy soil typical of the millet and fallow sites. Six aluminum access tubes of $44.5 \mathrm{~mm}$ external diameter ( $1.5 \mathrm{~mm}$ wall thickness) were installed for the purpose of calibration only. Two 16-s counts were taken at depths of 10, 20, 25, 30, 40,60, and 80 $\mathrm{cm}$. Three samples for gravimetric analysis were taken from each depth using cores $4.8 \mathrm{~cm}$ in diameter and $10.0 \mathrm{~cm}$ in length. The samples were taken less than $5 \mathrm{~cm}$ radially from the access tube. The calibration was conducted in October at the end of the rains. The soil around some of the access tubes was irrigated to obtain a range of water contents typical of those expected in the field during the wet season.

The results obtained from depths $30 \mathrm{~cm}$ were very similar to those obtained by Grime (1992) for similar depths. The data of Grime (1992) were therefore combined before performing the regression analysis which resulted in the standard linear form of the calibration equation:

$$
\theta_{\mathrm{v}}=a_{1}+b_{1}\left(\frac{N M_{\mathrm{c}}}{S T_{\mathrm{c}}}\right)
$$

where

$\theta_{\mathrm{v}}=$ volumetric soil water content, \%

$a_{1}=$ intercept constant

$b_{1}=$ slope constant

$N M_{\mathrm{c}}=$ neutron meter count

$S T_{\mathrm{c}}=$ standard count (in water drum)

with $a_{1}=-2.20$ and $b_{1}=74.13$ for this site. 
Data from the $10 \mathrm{~cm}$ depth were clearly different from those at deeper depths and a separate, quadratic calibration equation was derived using regression analysis for the data from this depth. The resulting quadratic equation was:

$$
\theta_{\mathrm{v}}=a_{2}+b_{2}\left(\frac{N M_{\mathrm{c}}}{S T_{\mathrm{c}}}\right)+c_{2}\left(\frac{N M_{\mathrm{c}}}{S T_{\mathrm{c}}}\right)^{2}
$$

where the terms are as described for Eq. (1) with $a_{2}=-3.9, b_{2}=181$, and $c_{2}=428$ for this site. While there was some evidence that data from the 20 and $25 \mathrm{~cm}$ depths behaved differently from those at depths $30 \mathrm{~cm}$, the difference was not considered sufficient to warrant a separate calibration equation. Data from the 20 and $25 \mathrm{~cm}$ depths were therefore converted to volumetric water content using Eq. (1).

Non-standard methods had to be used to calibrate the neutron probe at the tiger bush sites due to the very stony nature of the material. Two $500 \mathrm{~g}$ soil samples were taken from the pulverized soil blown out by motorized drills used for the installation of access tubes. The samples were oven dried and sent to the Centre d'Etudes Nucleaires de Cadarache in France. The samples were subsequently analyzed using the nuclear absorption-desorption technique described by Couchat et al. (1975). The mean of the results from the two samples were used for the calibration assuming a bulk density of $1.8 \mathrm{~g} \mathrm{~cm}^{-3}$. The resulting calibration equation has the same linear form as Eq. (1) with different constants $a_{3}$ and $b_{3}$. Constant $a_{3}$ varies from 3.64 to 62.41 for bulk densities ranging from 1.0 to $4.1 \mathrm{Mg} \mathrm{m}^{-3}$ (bulk density range from low density soils to certain iron minerals); $b_{3}$ varies from 96.7 to 104.2 for the same range in bulk density, assuming no change in the composition of the mineral fraction.

A difficulty with the method of Couchat et al. (1975) is that it allows for corrections to the calibration equation to be made when soil bulk density changes, but only if that change is due to a change in pore volume, i.e. not if the change in bulk density is due to a different composition of the soil solid (or mineral) fraction. In other words, the specific density and the neutron interaction characteristics of the solid fraction must remain unchanged. In the case of the lateritic tiger bush soil at the Southern and other supersites, changes in bulk density of the soil are often related to increases or decreases in the proportion of the solid fraction of the soil that consists of relatively heavy iron minerals (bulk density up to 4.1 $\mathrm{Mg} \mathrm{m}^{-3}$ ), in addition to simple increases or decreases in pore volume. In this case the specific density of the soil solid fraction does vary. This resulted in a potential difficulty in neutron probe calibration at the tiger bush sites. Indeed the reported volumetric soil water contents at the tiger bush sites appear very high compared to other vegetation covers. For this reason the data for soil water content from the tiger bush sites is shown as 'relative' in Figs. 14-17.

Calibration using the technique described by Couchat et al. (1975) does not account for escape of neutrons when measurements are made close to the soil surface, i.e. at depths less than 15 to $20 \mathrm{~cm}$. It is this escape of neutrons from the soil surface, without the opportunity to be reflected back to the counter after impact with hydrogen atoms, which required use of the two calibration equations indicated above as Eqs. (1) and (2). Parkes and Siam (1979), using a technique proposed by Grant (1975), published correction factors to convert observed count ratios $\left(N M_{\mathrm{c}} / S T_{c}\right)$ in the surface layers to corrected count ratios, i.e. the count ratio which would occur if there were uniform soil conditions in all directions 
from the neutron source. These correction factors gave results which compared favorably with water contents in the surface layers determined gravimetrically in the millet and fallow sites. The Parkes and Siam (1979) correction factors were therefore applied to data from the $10 \mathrm{~cm}$ depth in the tiger bush before application of the linear regression equation for $\theta_{\mathrm{v}}$.

Similar gravimetric calibration techniques for the neutron probe were carried out at the Central Site East except that bulk density measurements were made at the time of calibration tube installation using a gamma probe (Bertuzzi et al., 1987). Samples from the tiger bush site were also sent to the Centre d'Etudes Nucléaires de Cadarache in France. Calibration equations in the form of Eq. (1) were developed for each site in which the intercept term $a_{1}$ varied as a function of depth and the slope term $b_{1}$ was maintained as a constant for each site. $b_{1}$ varied from a low of 66 in the millet to a high of 92 in the tiger bush, while $a_{1}$ varied from 3.7 at depths below $280 \mathrm{~cm}$ to 0.2 at $10 \mathrm{~cm}$ depth in the millet and from 18.0 at depths below $30 \mathrm{~cm}$ to 15.0 at $10 \mathrm{~cm}$ depth in the tiger bush. Three individual neutron probes were cross-calibrated against the one probe used in the calibration process based on intercomparison of the count ratio made by all probes in seven access tubes covering relatively moist to relatively dry soil conditions.

\subsubsection{Time domain reflectometer (TDR)}

TDR measurements are based on the difference in the dielectric constants of water (80), air (1), and soil particles (about 8 ). The dielectric constant is calculated as a function of the speed of light, the time of travel of the TDR signal in parallel rods inserted into the medium being measured and the length of the rods (Roth et al., 1990). Measurements at the Central Site West were made using three instruments; a Tektronix cable-tester in combination with automatic waveform analysis (Heimovaara and Bouten, 1990), and the FOM/m system and FOM/mts system of Easy Test both of which display water content through internal conversion of travel times. The accuracy of the internal conversion was not adequate and laboratory calibration was made to determine an equivalent dielectric constant and calibration to soil water content for all systems. The calibration concentrated on the dry range of soil water content, resembling expected field conditions.

Fourteen undisturbed samples were taken from different subsites of the Central Site West for TDR calibration. Nine additional samples were packed in the laboratory to a density comparable with the undisturbed samples to analyze the very dry range. The samples were taken in PVC rings with a diameter of $8 \mathrm{~cm}$ and length of $12 \mathrm{~cm}$. A 10$\mathrm{cm}$-long two-rod TDR sensor was placed in the center of the samples and travel times and volumetric soil water content measured. Three dielectric constants were determined for each sample - one using the travel time for the cable-tester and one each using the internal calibration curve of the FOM/m and FOM/mts units. The dielectric constant determined using the cable-tester was chosen as the standard and the results from the FOM/m and FOM/mts units were adjusted to give identical dielectric constants. The equations to convert the dielectric constants of the FOM/m and FOM/mts units to the calibration standard were:

$$
\begin{aligned}
& \varepsilon_{\mathrm{cal}(\mathrm{m})}=-1.92 \times 10^{-3} \varepsilon_{\mathrm{m}}^{3}+5.76 \times 10^{-2} \varepsilon_{\mathrm{m}}^{2}+0.4301 \varepsilon_{\mathrm{m}}+1.311 \\
& \varepsilon_{\mathrm{cal}(\mathrm{mts})}=-1.44 \times 10^{-3} \varepsilon_{\mathrm{mts}}^{3}+6.63 \times 10^{-2} \varepsilon_{\mathrm{mts}}^{2}+0.1288 \varepsilon_{\mathrm{mts}}+2.213
\end{aligned}
$$


where $\varepsilon_{\mathrm{m}}$ and $\varepsilon_{\mathrm{mts}}$ are the original values and $\varepsilon_{\mathrm{cal}}$ is the corrected value corresponding to the value of the dielectric constant of the cable tester. The dielectric constant $\varepsilon_{\mathrm{cal}}$ was calibrated to volumetric soil water content by,

$$
\theta\left(\varepsilon_{\text {cal }}\right)=3.08 \times 10^{-4} \varepsilon_{\text {cal }}^{3}-7.6 \times 10^{-3} \varepsilon_{\text {cal }}^{2}+8.11 \times 10^{-2} \varepsilon_{\text {cal }}-0.1732
$$

Calibration for TDR at the Central Site East was made in situ in parallel with measurement of density made with a gamma probe (Bertuzzi et al., 1987). Soil water content on a mass basis was measured corresponding to each measure of density which allowed for computation of the volumetric soil water content. TDR measurements were made simultaneously at the same locations to derive the calibration equation. The final calibration for volumetric soil water content on a mass basis $\left(\mathrm{m}^{3} \mathrm{~m}^{-3}\right)$ differed from that given by Topp et al. (1980) according to the following,

$$
\theta_{\mathrm{c}}=0.013+0.614\left(\theta_{\mathrm{T}}\right)
$$

in which $\theta_{\mathrm{c}}$ is the calibrated value and $\theta_{\mathrm{T}}$ is the value given in the original expression from Topp et al. (1980) based on the dielectric constant $\varepsilon$,

$$
\varepsilon=3.03+9.3\left(\theta_{\mathrm{T}}\right)+146\left(\theta_{\mathrm{T}}\right)^{2}-76.3\left(\theta_{\mathrm{T}}\right)^{3}
$$

\subsubsection{Capacitance probe}

The surface capacitance insertion probe (SCIP) developed by the Institute of Hydrology was used for measurement of surface soil water content at the Southern Site (Dean et al., 1987). The SCIP was calibrated using the procedure described by Robinson and Dean (1993). The cores used to take gravimetric samples were $4.9 \mathrm{~cm}$ in diameter and $5.0 \mathrm{~cm}$ in length. Initial analysis of the SCIP calibration data for Niger suggested that, over the range of water contents measured, a linear calibration equation was appropriate. However, closer inspection of the data revealed that a linear equation sometimes predicted negative water contents. Additional statistical analysis of probe readings and gravimetric samples resulted in a regression equation of the form:

$$
\theta_{v}=\frac{a_{4}}{\left(S C I P_{c}\right)^{2}}+b_{4}
$$

where $S C I P_{\mathrm{c}}=$ capacitance probe reading. An inter-comparison of the SCIP unit used for field calibration and other SCIP units was made in the laboratory to develop consistent calibration equations for all of the probes. In this way the following $a_{4}$ and $b_{4}$ constants, respectively, were determined for each of the three SCIP units used: 110.81 and 41.66 for SCIP $7143 ; 125.15$ and 46.54 for SCIP $7112 ; 121.86$ and 45.48 for SCIP 353.

Fitting the Niger data to Eq. (8) accounted for much of the data variance $\left(r^{2}=0.95\right)$ and removed negative predictions from the calibration data set. The final $a_{4}$ and $b_{4}$ constants did not eliminate all 'negative soil water contents' measured using the SCIP during the IOP. The 'negative soil water contents' that remain are probably a measure of the accuracy to which soil water content can be determined using the SCIP, particularly at the very low soil water contents experienced in Niger. 


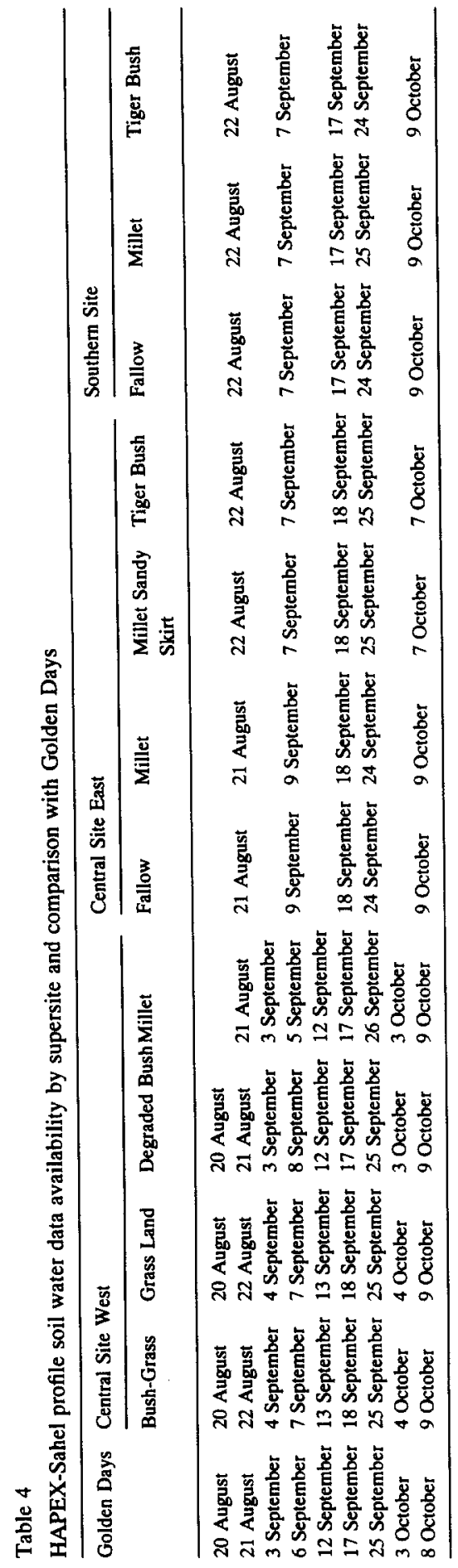




\section{Profile and surface soil water content - spatial and temporal variability}

\subsection{Profile soil water data}

The effects of the rainfall gradient over the HAPEX-Sahel experimental domain during the IOP and, more importantly, the localized redistribution of rainfall is demonstrated by the plots of profile soil water. Soil crust conditions control runoff, runon, and preferential infiltration resulting in the redistribution of rainfall in the soil profile. This redistribution complicates the interpretation of the effects of the rainfall gradient on vegetation and the local energy balance. This complication can be reduced by evaluation of profile soil water conditions for representative sites within the various vegetation covers monitored during the experiment. This section presents a sample of the data available within the data base which makes up the HAPEX-Sahel Information System (HSIS). Selection of the available profile soil water data for this article was based on experimental 'Golden Days' on which all teams were encouraged to make a maximum data collection effort. Table 4 indicates the HAPEX-Sahel Golden Days and the corresponding availability of profile data for each supersite and vegetation cover. This is only a subset of the available soil water content data in HSIS.

The millet vegetation cover has been selected to demonstrate the variation of soil water content over the three supersites during the IOP. Figs. 1-9 display the volumetric soil water content as a function of depth and the total stored soil water over the profile for the different sites. The recorded precipitation from the nearest EPSAT (Estimation des Précipitations par SATellite) (Taupin et al., 1993) raingauge is also plotted with the stored soil water time series. The figures show data from a site (neutron probe access tube) determined to be relatively wet and from one determined to be relatively dry, compared with other sites within the same vegetation cover and supersite. Recall that generally ten sites were monitored per type of vegetation at each supersite.

The profile soil water data were used to calculate the amount of stored soil water in the profile for the various dates. The volumetric soil water content measured within each depth layer was assumed to be valid over the interval defined by half the distance between successive neutron probe readings. The total depth of the profile considered for calculation of the storage is indicated in the figures for each vegetation cover. No attempt was made to fit a smooth curve through the soil water data as a function of depth before calculating the storage, although this may be recommended for certain applications. The fact that the neutron probe is sampling over a spherical volume with a radius in the range of $0.3 \mathrm{~m}$ in dry sand means that there is already an averaging process.

The first striking feature of the graphs is the very low levels of soil water content displayed, even for the wet locations and following rainfall events. This is a feature of the very sandy soils common in the Sahel which occupied the project area. This is in sharp contrast to typical conditions in a more temperate environment in which soil water values two to three times larger would be expected in soils with greater proportions of silt and clay. While calibration for the absolute value of soil water content measured with a neutron probe is always difficult, it can be seen that all three supersites show consistently low moisture levels even though different teams performed their own calibration for each site. Owing to the physical characteristics of the neutron probe, the differences in moisture 


\section{Volumetric Soil Water Content (\%)}

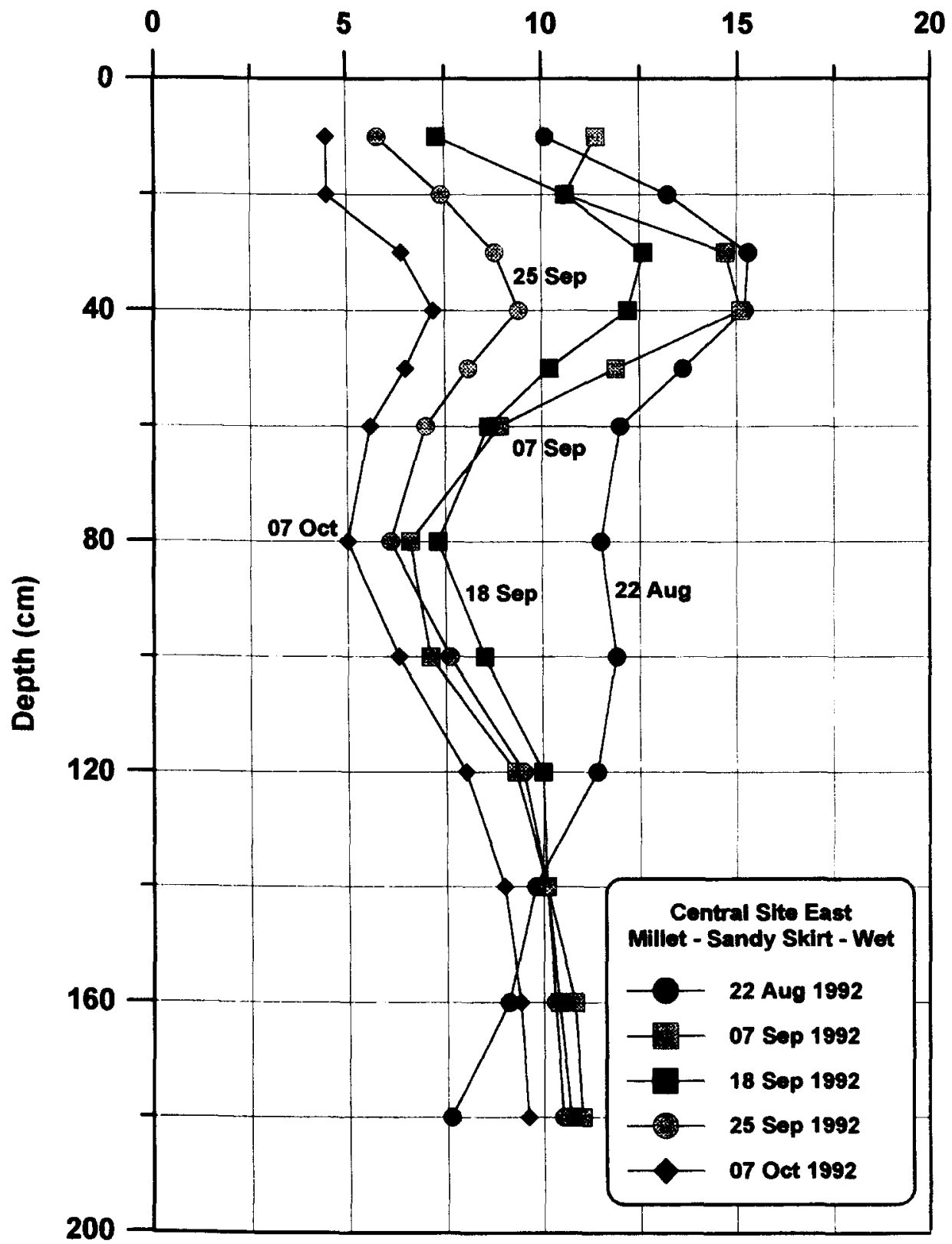

Fig. 1. Profile soil water content for Central Site East, millet vegetation cover on sandy skirt, relatively wet location. 


\section{Volumetric Soil Water Content (\%)}

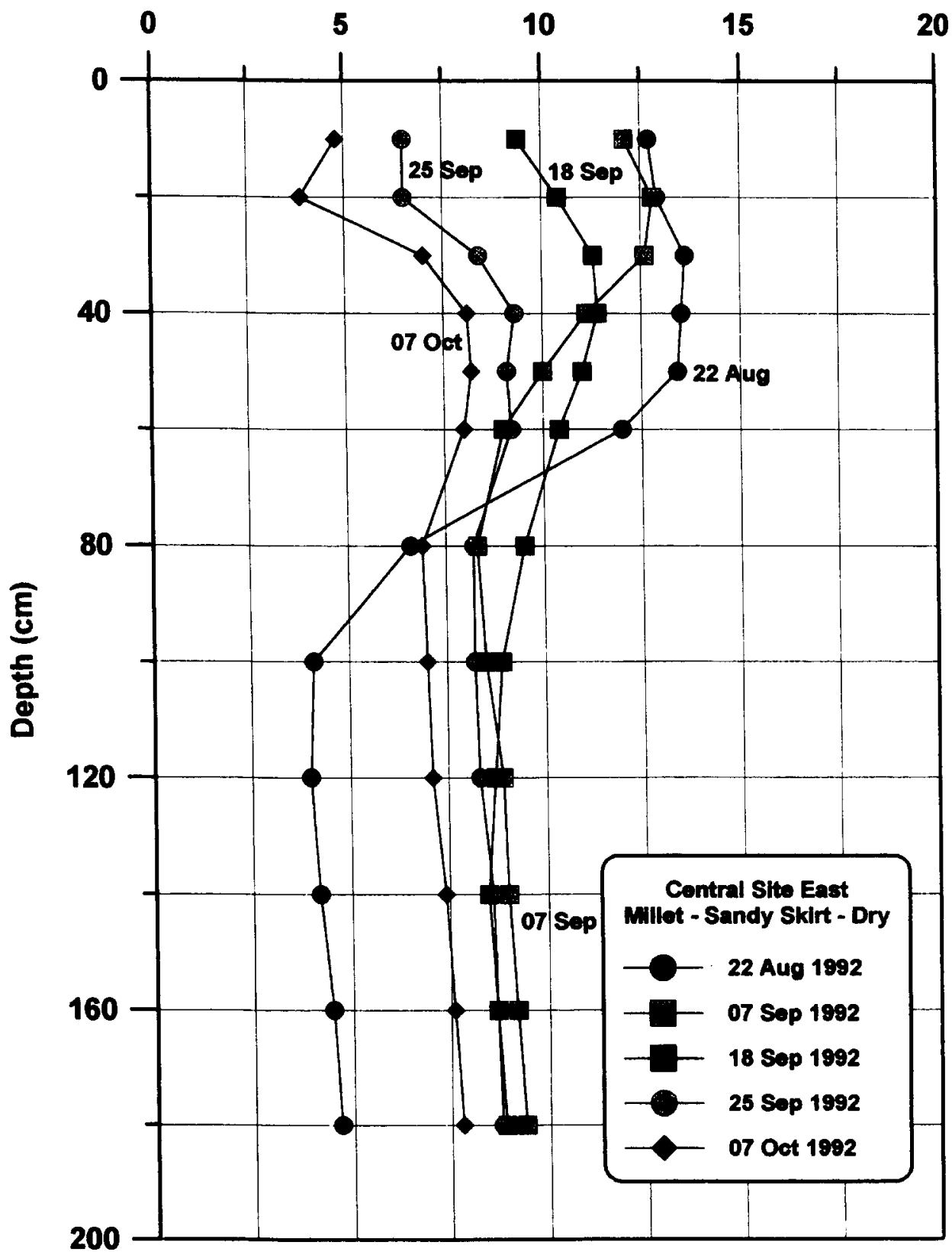

Fig. 2. Profile soil water content for Central Site East, millet vegetation cover on sandy skirt, relatively dry location. 


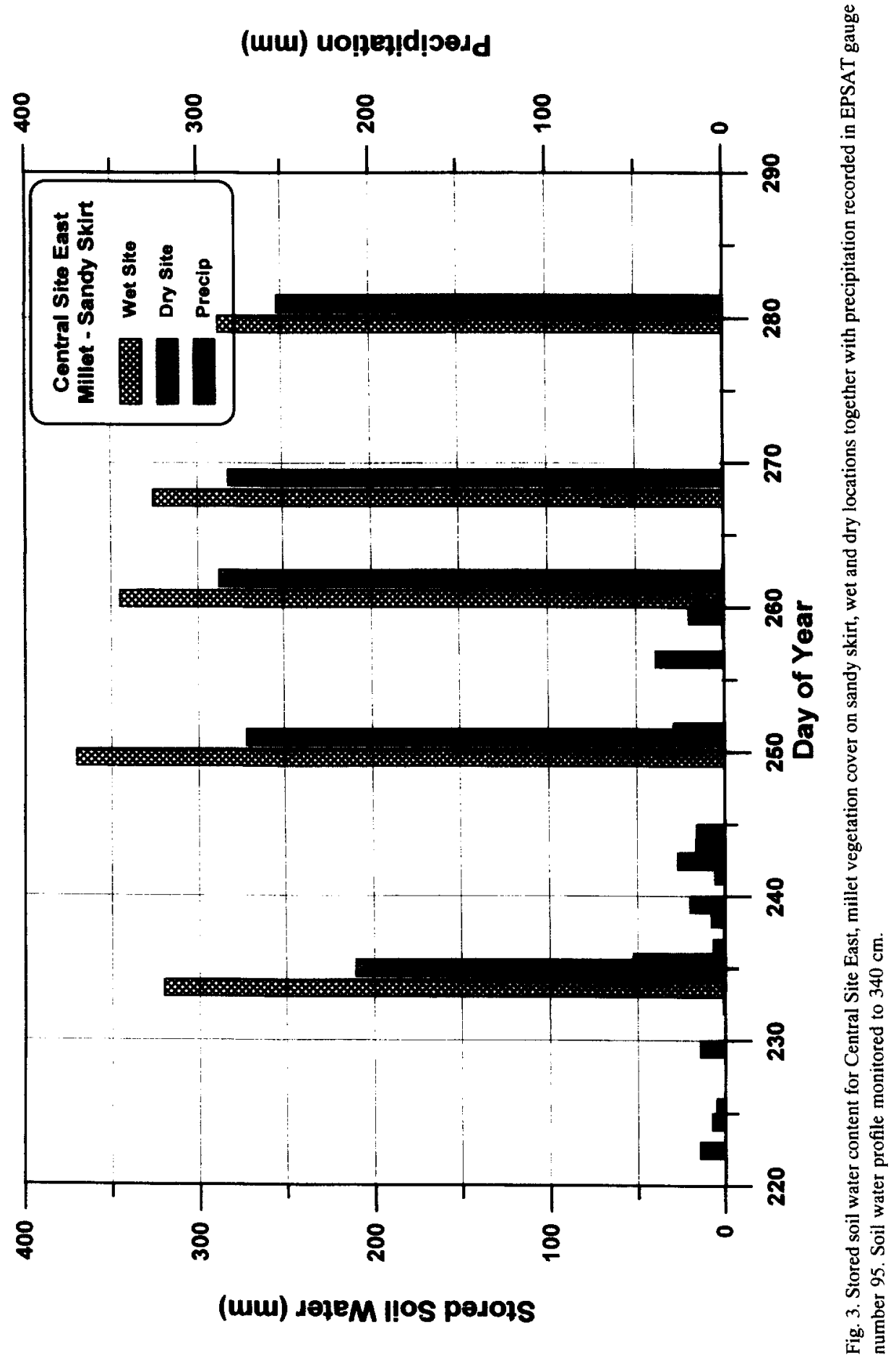




\section{Volumetric Soil Water Content (\%)}

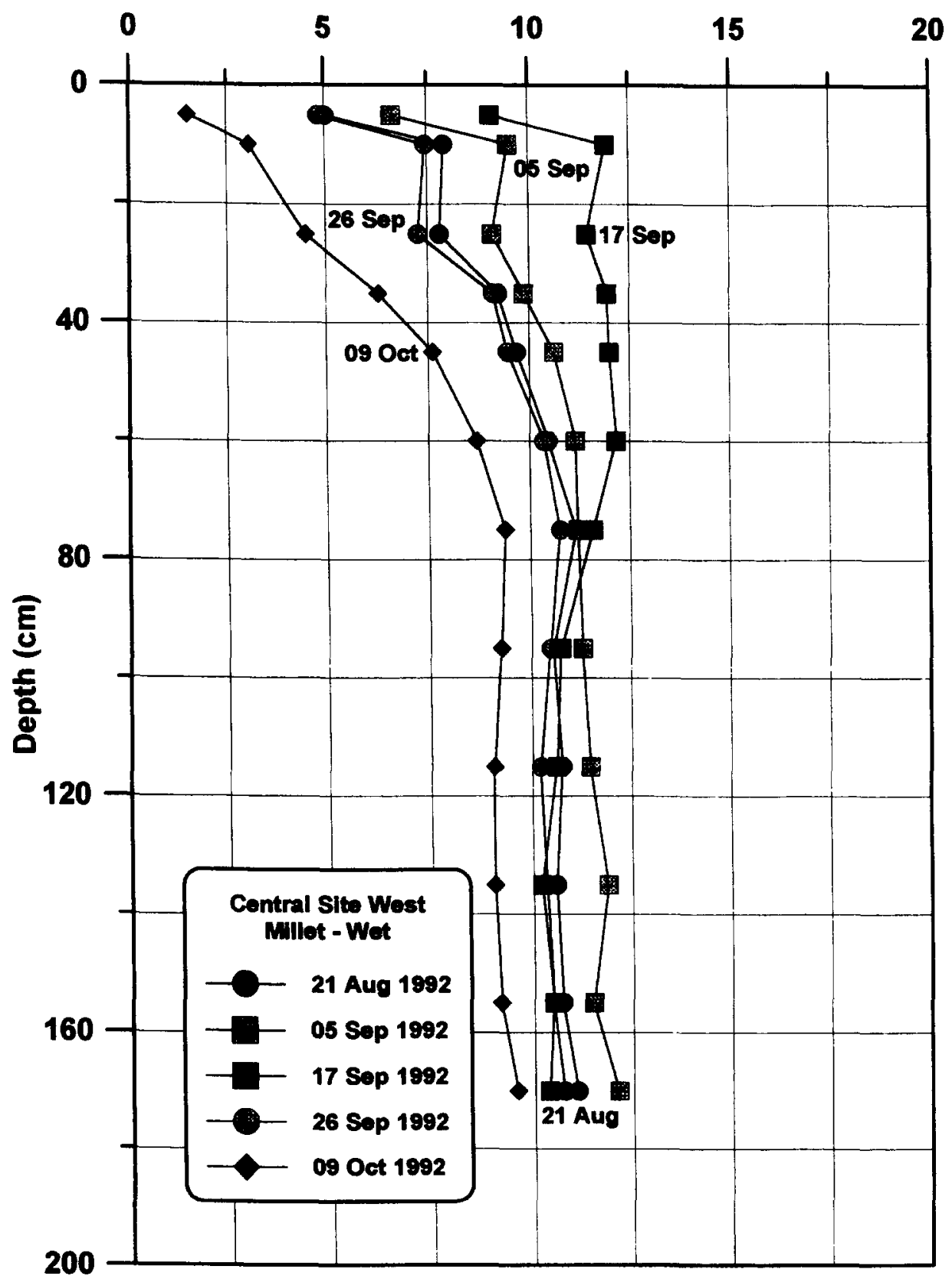

Fig. 4. Profile soil water content for Central Site West, millet vegetation cover, relatively wet location. 


\section{Volumetric Soil Water Content (\%)}

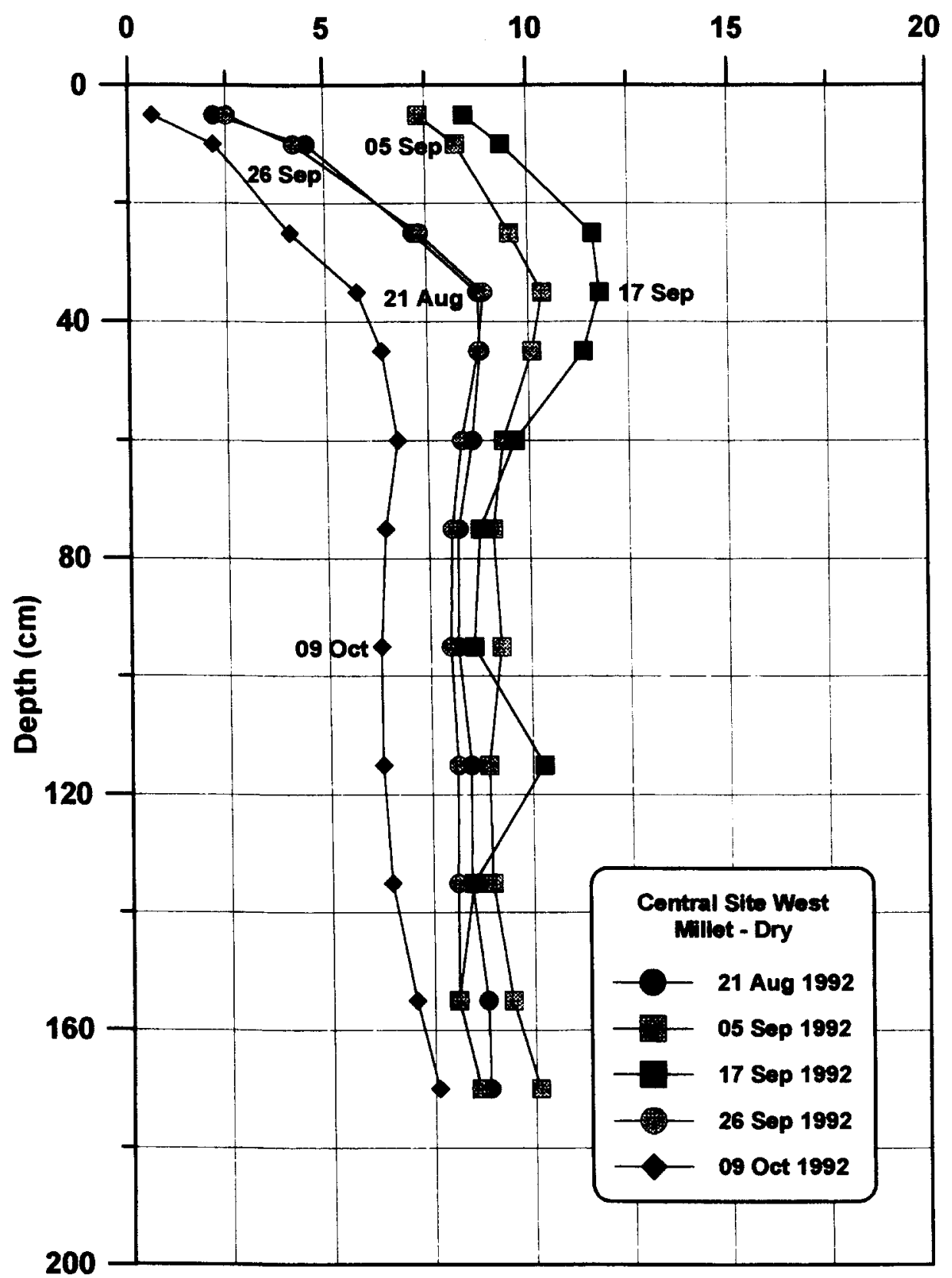

Fig. 5. Profile soil water content for Central Site West, millet vegetation cover, relatively dry location. 


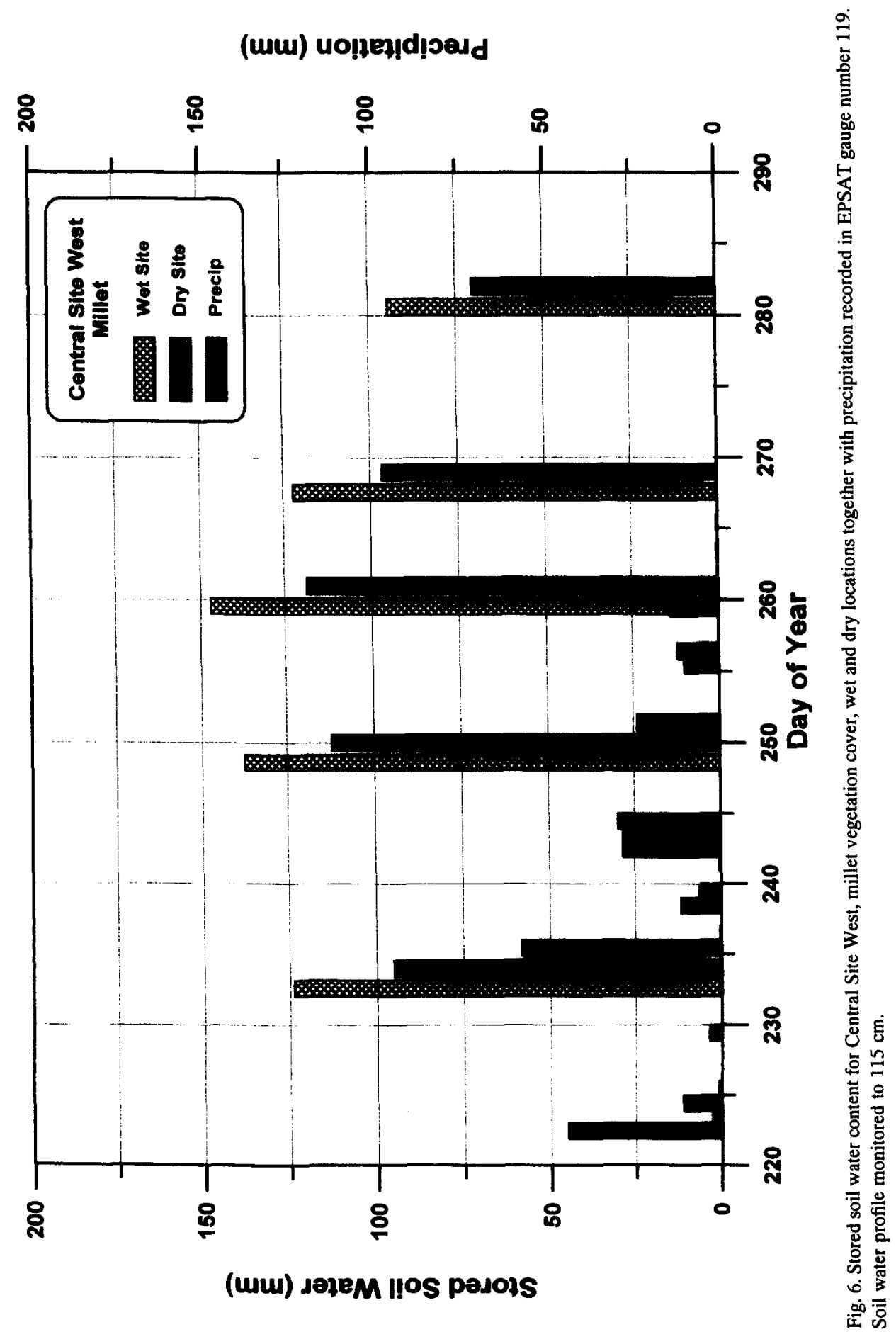


Volumetric Soil Water Content (\%)

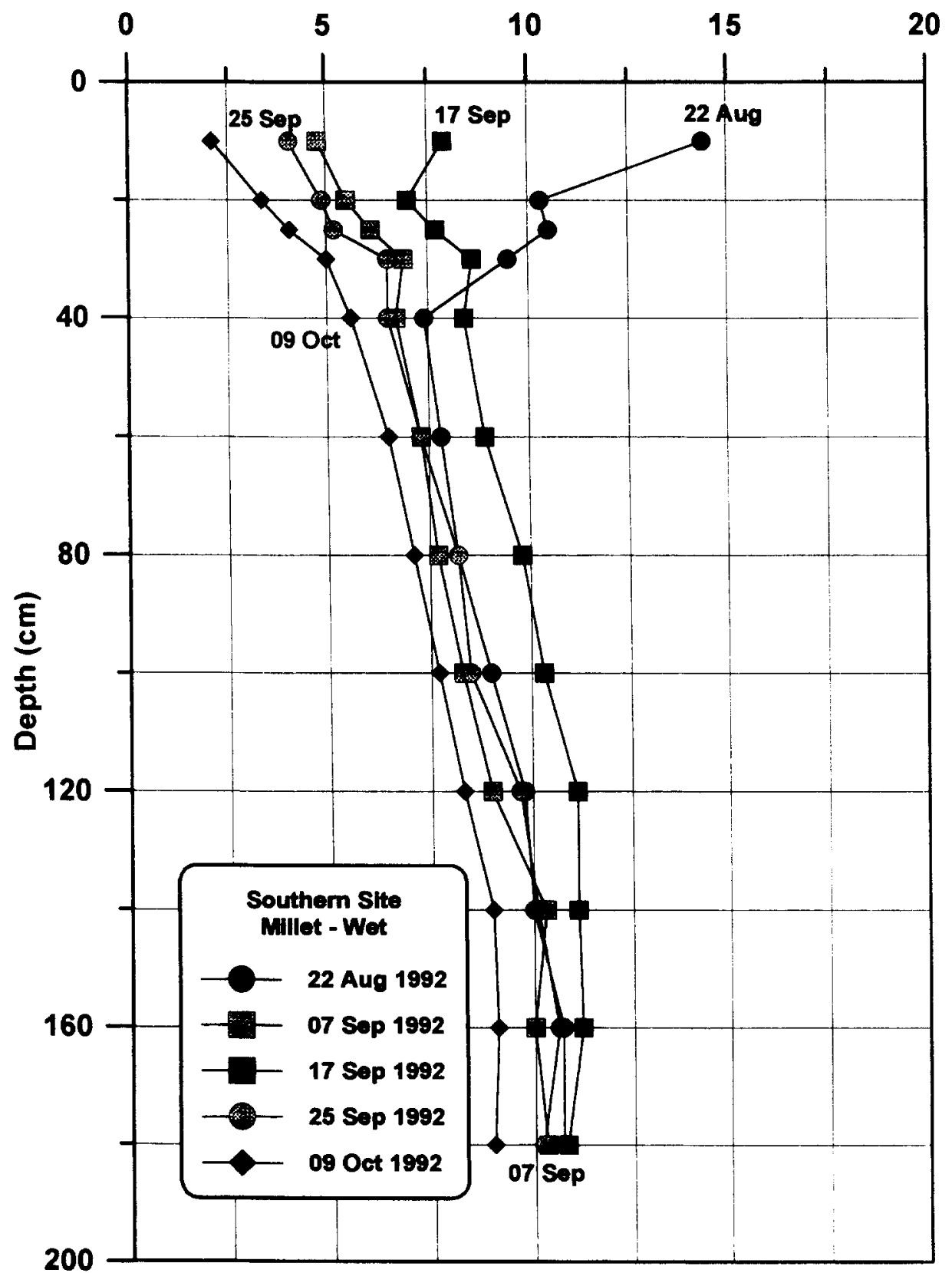

Fig. 7. Profile soil water content for Southern Site, millet vegetation cover, relatively wet location. 


\section{Volumetric Soil Water Content (\%)}

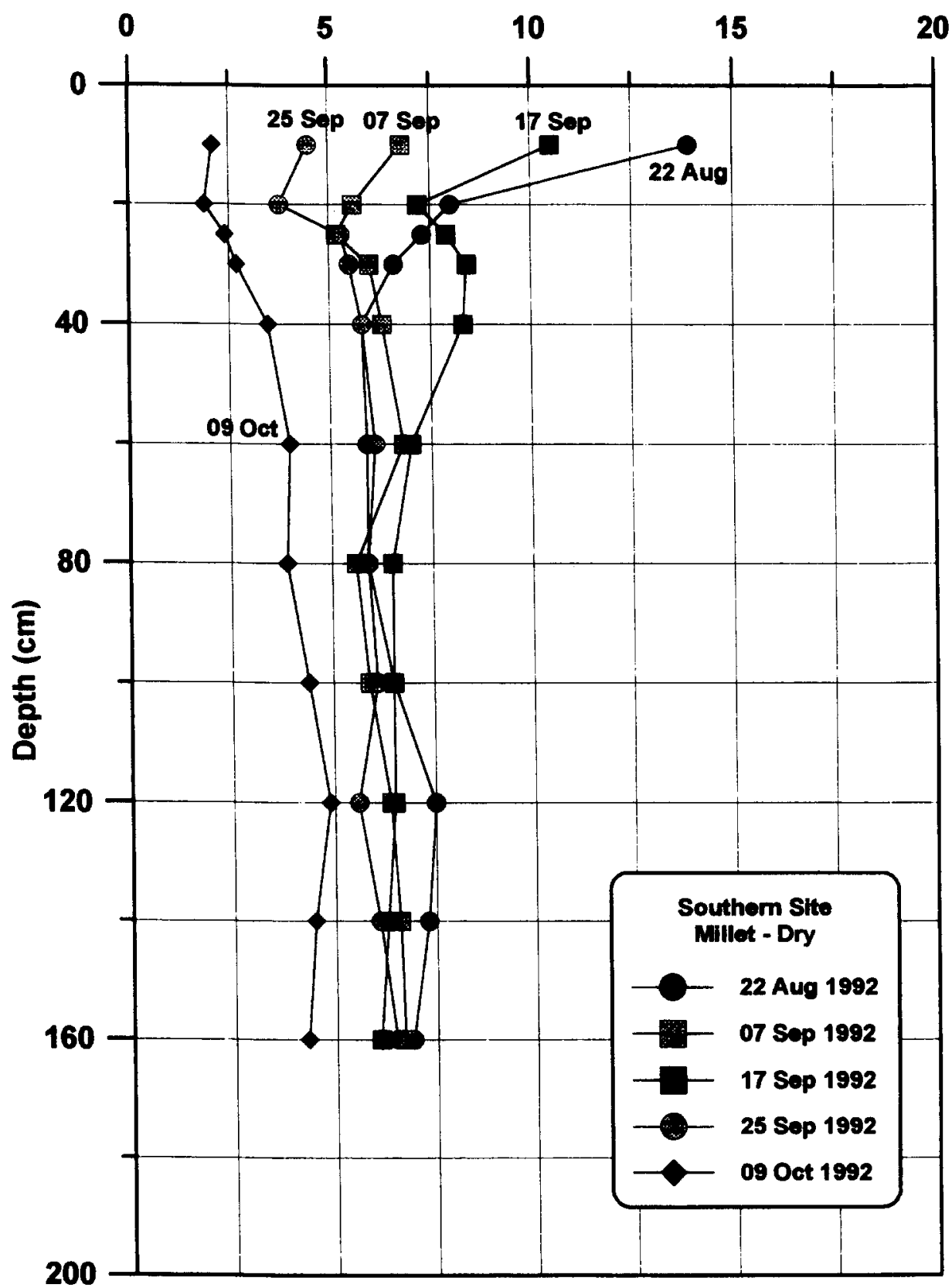

Fig. 8. Profile soil water content for Southern Site, millet vegetation cover, relatively dry location. 


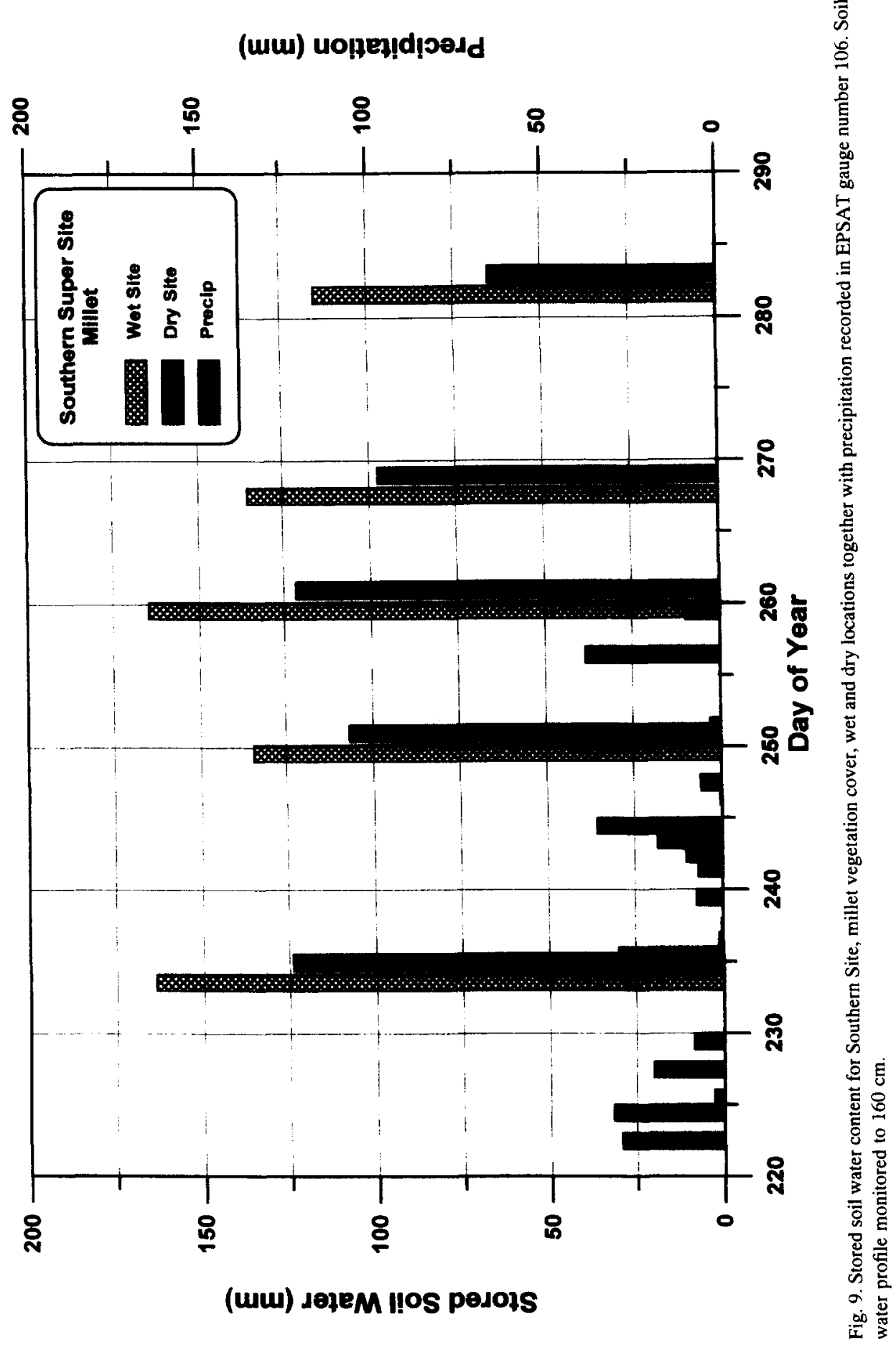


content between any two dates of measurement are less subject to error than the absolute value (Haverkamp et al., 1984; Vauclin et al., 1984; Vandervaere et al., 1994a,b).

Figs. 1-3 show data for both the dry and wet locations within the millet on a sandy skirt 'wind aligned blob' (WAB) of the Central Site East. Both locations show the effects of rewetting of the profile by rainfall, and possible runon, between 22 August (day of year (DOY) 235) and 7 September (DOY 251) and subsequent drying down of the profile until the end of the IOP on 7 October (DOY 281). This is clearly observed in the plot of stored soil water combined with precipitation in Fig. 3. The penetration of surface infiltration to depths exceeding $2 \mathrm{~m}$ after 22 August (DOY 235) can be observed for both locations. Normally soil water profiles exhibiting a gradual drying down of the profile, as indicated by almost parallel soil water content traces towards the bottom of the profile, are evidence of gradual drainage, while soil water extraction at a higher rate, as indicated towards the upper part of the soil horizon, is an indication of additional mechanisms, i.e. evaporation and transpiration. However, only a detailed analysis of the total potential profile and subsequent location of the zero-flux plane separating downward drainage from upward evaporation and transpiration can be used to determine the probable limit of soil water extraction by roots.

Figs. 4-6 show profile soil water data from wet and dry locations of the millet WAB at the Central Site West. Both sites are subject to wetting by rainfall until 17 September (DOY 261) and gradual drying with time until the end of the IOP. Subject to the limitations described in the preceding paragraph, the majority of the water uptake by roots and soil evaporation appears to take place in the upper 60 to $80 \mathrm{~cm}$ of the profile for both locations. Figs 7-9 indicate patterns for wet and dry locations of the millet WAB in the Southern Site. Fig. 8 (dry) demonstrates the potential difficulty with neutron probe calibration at the shallowest reading, in this case at $10 \mathrm{~cm}$ depth. For most of the dates displayed there is an apparent reversal of the moisture gradient with depth at the surface. Such a reversal is possible under conditions of repeated, light rainfall, but is very unlikely for the environmental conditions experienced in the Sahel. Potential explanations are inadequate compensation for neutron escape in the surface layer calibration and/or a systematic uncertainty in the depth of the neutron source for the first reading at $10 \mathrm{~cm}$ depth. This systematic error would not be as evident in deeper locations due to the radius of influence of the volume monitored by the probe (Cuenca, 1989).

The stored soil water displayed in Fig. 9 does not follow the pattern demonstrated in Figs. 3, and 6 for the other sites. The data indicate a decrease in storage between 22 August (DOY 235) and 7 September (DOY 251) for both the wet and dry sites in spite of rainfall measured at the nearest EPSAT gauge. The explanation gives an idea of the care required in interpreting soil water measurements. The rainfall indicated on 22 August (DOY 235) fell before dawn while the neutron probe measurements were made in the afternoon of the same day, therefore reflecting a relatively wet profile. The next significant rainfall pattern ends on 1 September (DOY 245), some 6 days before the neutron probe measurements on 7 September (DOY 251). With the profile being relatively wet at the time of rainfall, it is not surprising that there was significant drainage and evapotranspiration before the next neutron probe measurement on 7 September (DOY 251).

Differences between the wet and dry tubes in the millet are most apparent in the upper part of the soil profile relative to differences at the fallow sites (not shown) which extend 
over the total depth of measurement ( $200 \mathrm{~cm}$ or more). This is thought to be related to two factors. First, differences in surface conditions are more extreme at the fallow sites than at the millet sites. The fallow vegetation is more patchy than the millet and in between the bushes and grass patches in the fallow there are more severely crusted areas than in the millet. Short distance spatial variability in the runoff, runon, and evapotranspiration is therefore more marked in the fallow, leading to more marked differences in point water balances than in the millet. While large differences can also be found in the millet, there are fewer patches with a very 'dry' water balance. Second, the sampling scheme chosen for soil water monitoring makes the chances of finding such differences smaller. When the sampling scheme is adapted to the situation in the millet, i.e. by stratified random placement of access tubes in areas of low, medium and high degrees of crusting, very extreme differences in runoff, runon and the water balance can be found in that vegetation type as well (Gaze et al., 1997).

Figs. 10 and 11, for profile soil water content, and Figs. 12 and 13, for stored soil water, compare wet and dry locations on different dates for bush-grassland and grassland vegetation covers at the Central Site West. For different dates and the same vegetation cover, it can be observed that while there is a significant change in soil water content over the WAB in response to environmental conditions, the wetter location consistently has a higher level of soil water storage than the dry location. Both sites respond to the precipitation indicated in Figs. 12 and 13. The relatively small increase in stored soil moisture between 20 August (DOY 233) and 4 September (DOY 248) in spite of significant precipitation points towards strong evapotranspiration during this period of rapid vegetation growth. These figures clearly demonstrate the principle that within a given site, i.e. for a given soil texture and vegetation cover, wet sites tend to stay wetter and dry sites remain drier than other locations throughout the season (Vachaud et al., 1985). This principle, which is important in the design of soil moisture monitoring schemes, is also clear in Fig. 3, Fig. 6, and Fig. 9.

Figs. 14 and 15 demonstrate profiles in both the bare soil strip and vegetation strip for the tiger bush WAB of the Central Site East which aid in understanding the hydrologic balance in this WAB. These figures indicate that changes in soil water due to rainfall in the bare soil strip are limited to the top $50 \mathrm{~cm}$ or less of the profile while changes in the vegetation strip extend throughout the monitored profile. (The total depth monitored was $340 \mathrm{~cm}$ of which $200 \mathrm{~cm}$ are shown to maintain uniformity with Figs. 16 and 17.) The capacity for infiltration of rainfall in the bare soil strip is extremely limited, resulting in almost all the incident rainfall running off from the bare soil into the adjacent vegetated area. The hydrologic balance within the vegetated area is subject to direct infiltration of rainfall and runon, particularly at the upslope edge of the vegetation strip. With regard to Figs. 14 and 15, the sharp contrast in the decrease in soil water content with time towards the top of the soil profile indicates that the latent heat, or evaporative, flux from the vegetation strip is significantly higher than that for the bare soil, thereby generating localized advective conditions within the tiger bush WAB.

Figs. 16 and 17 are again a dramatic demonstration of the sharp discontinuity in the hydrologic and energy balance for the tiger bush locations, in this case for the Southern Site. Very little infiltration of rainfall is apparent for the bare soil location with the possible influence limited to about $30 \mathrm{~cm}$ depth. Under the vegetated area soil water changes with 


\section{Volumetric Soil Water Content (\%)}

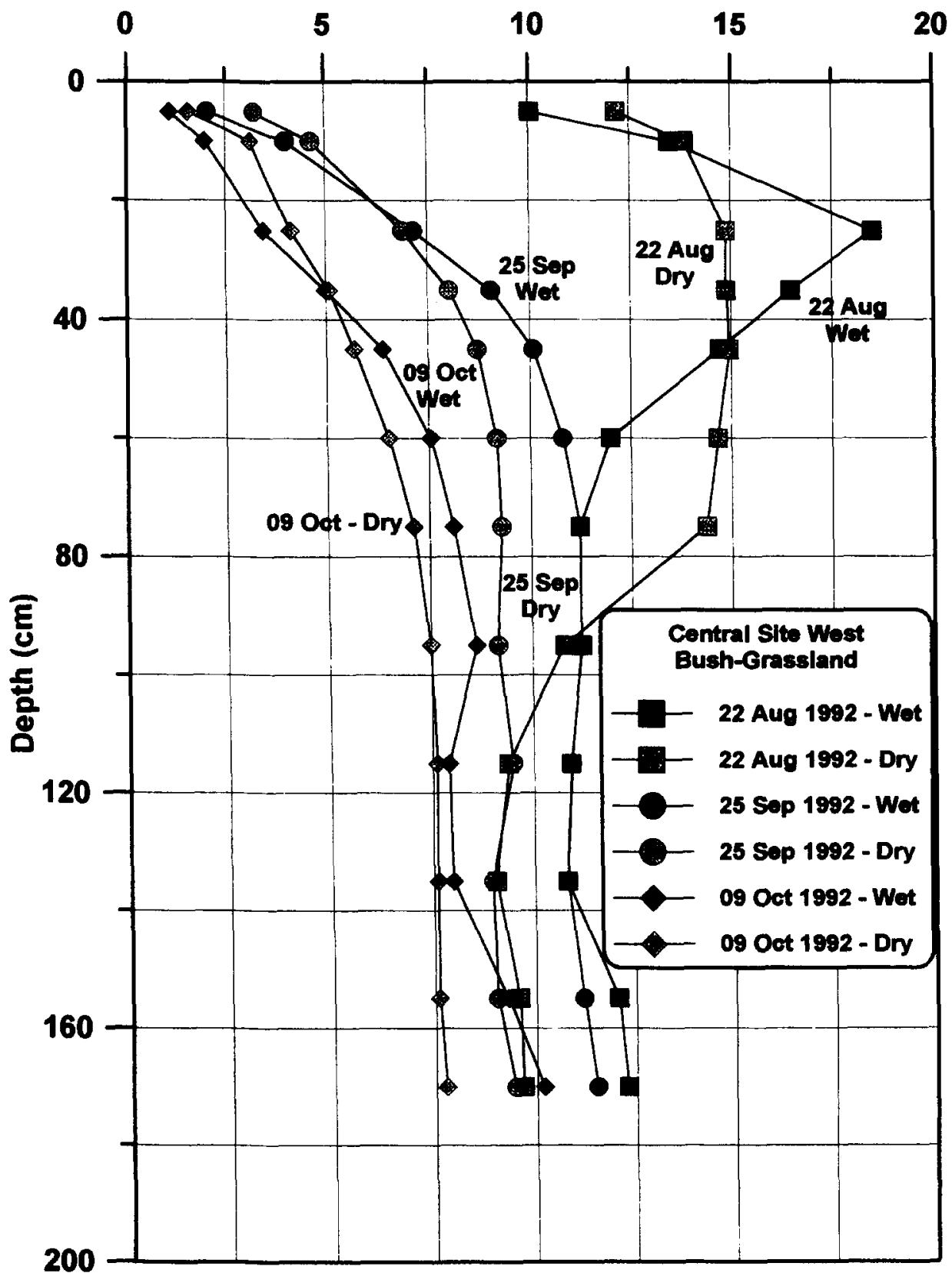

Fig. 10. Profile soil water content for Central Site West, bush-grassland vegetation cover, comparison of wet and dry locations for representative dates. 


\section{Volumetric Soil Water Content (\%)}

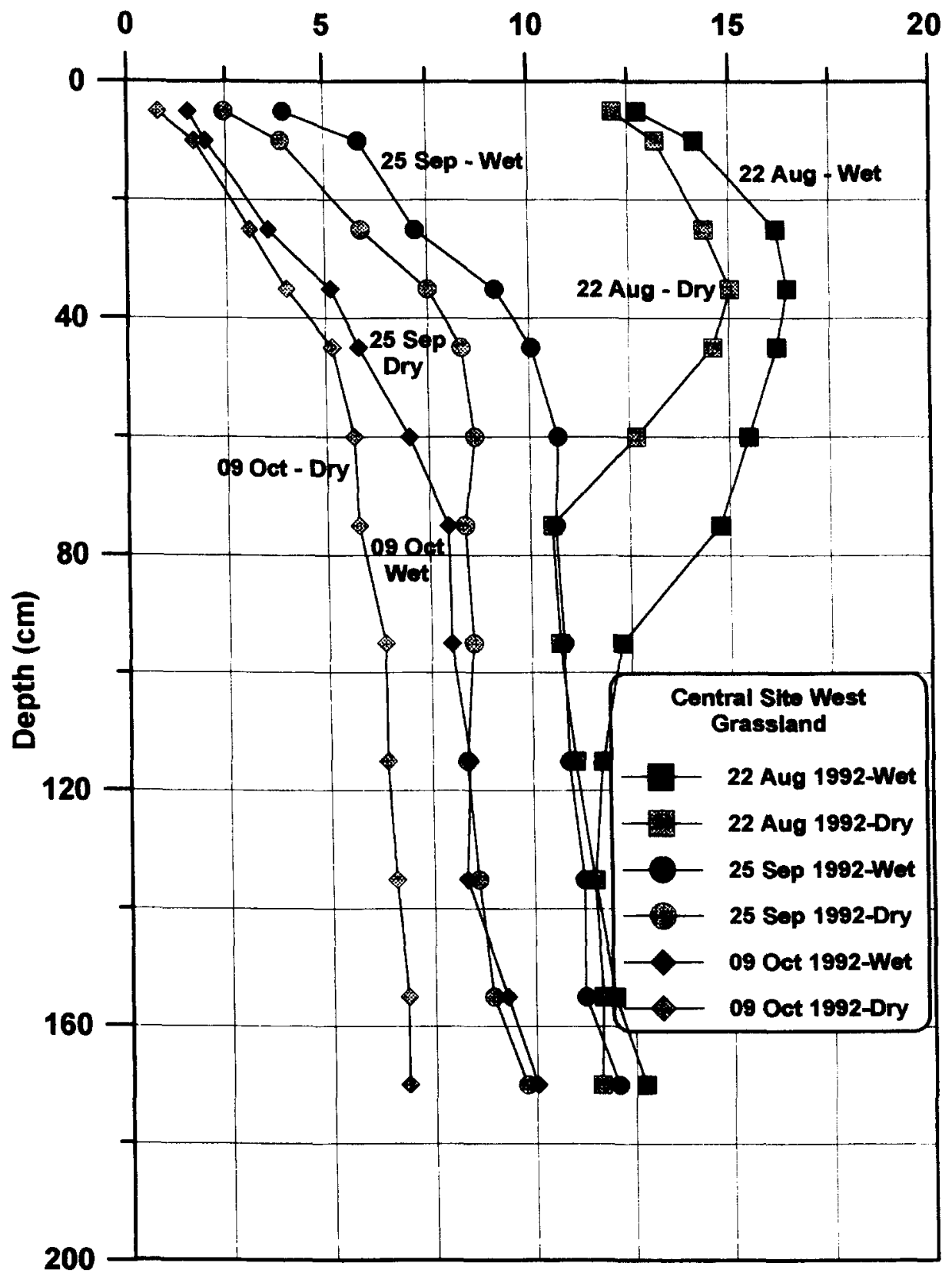

Fig. 11. Profile soil water content for Central Site West, grassland vegetation cover, comparison of wet and dry locations for representative dates. 


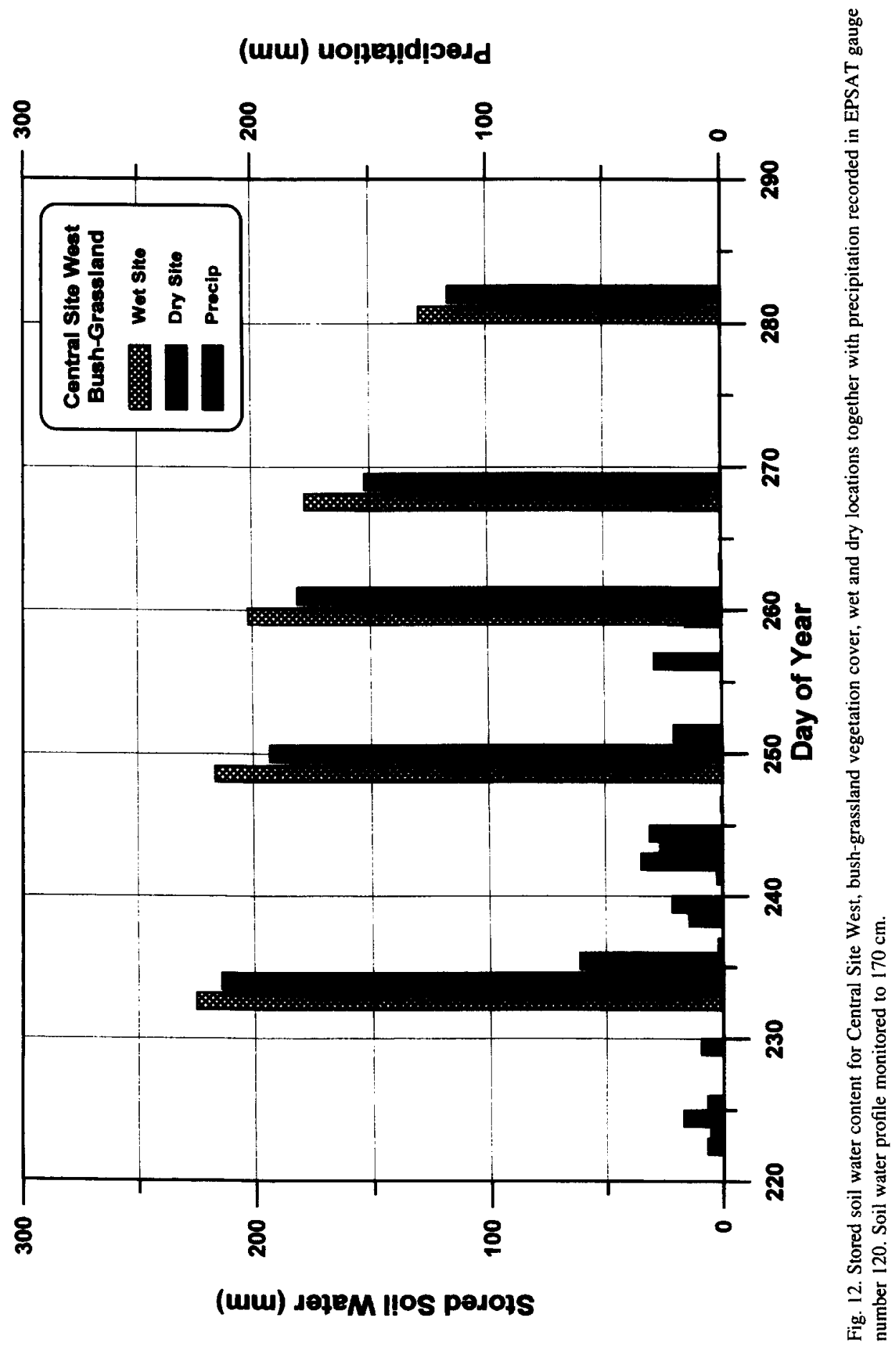




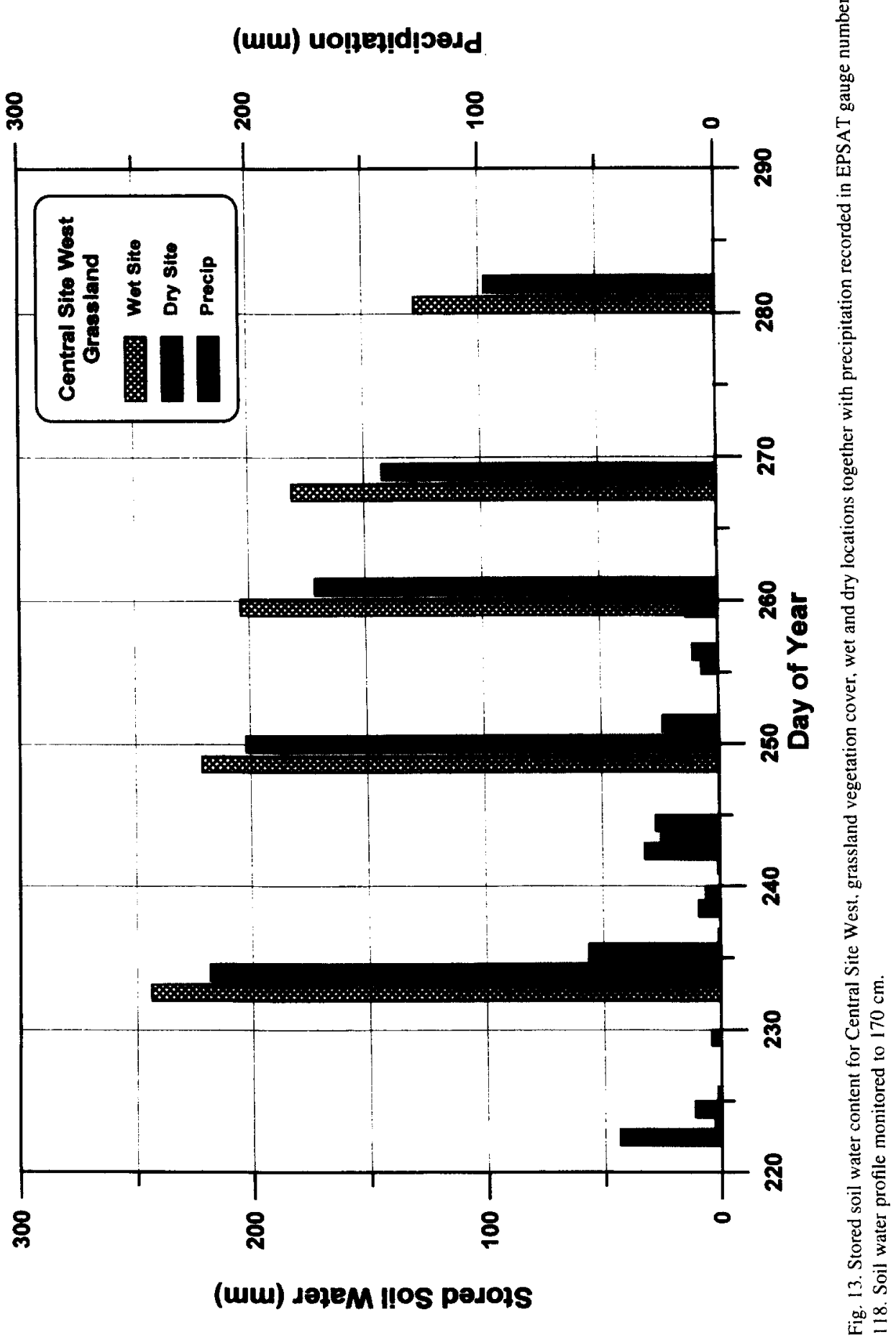




\section{Relative Volumetric Soil Water Content (\%)}

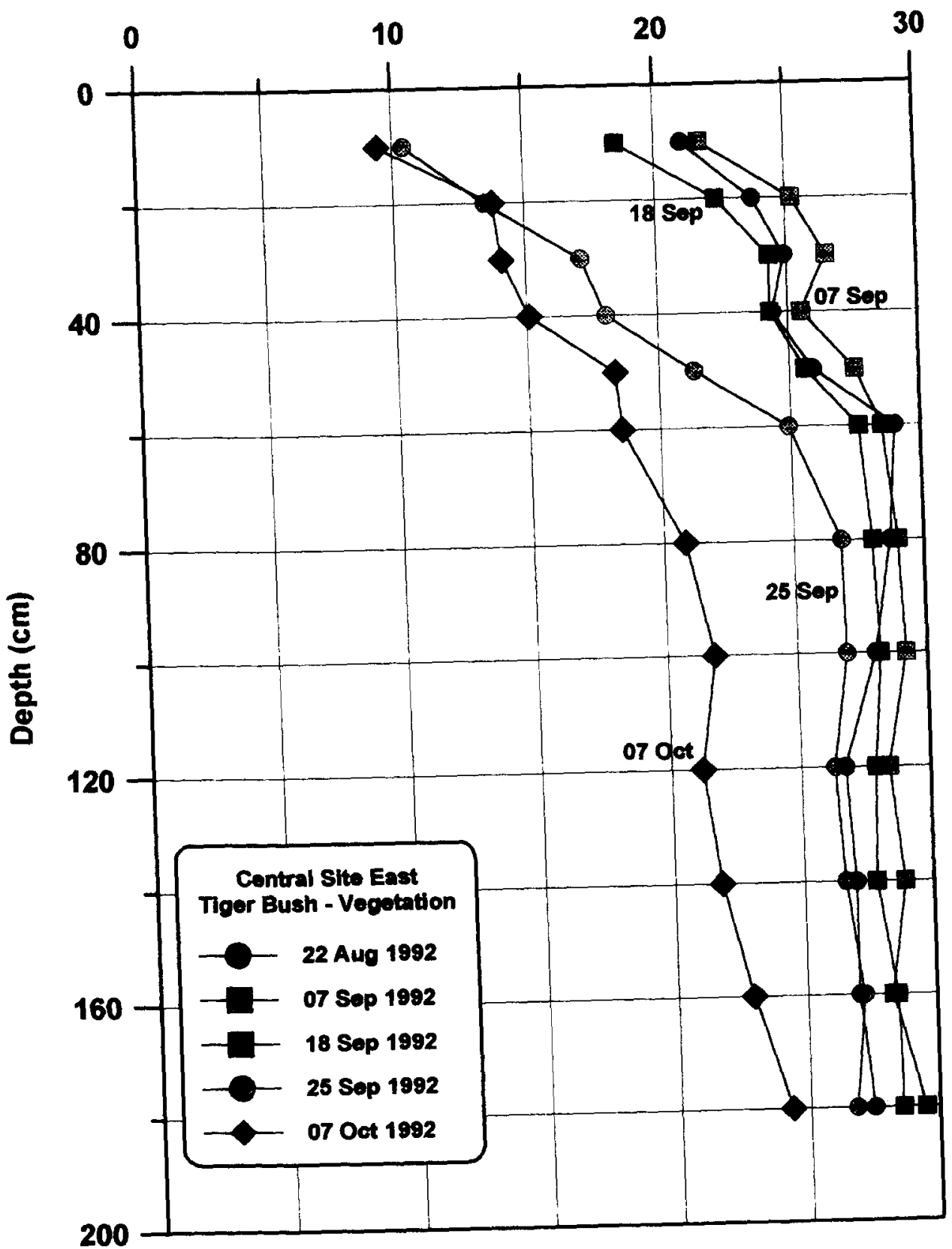

Fig. 14. Profile soil water content for Central Site East, tiger bush vegetation cover, vegetation strip. (Absolute values are uncertain due to the presence of iron minerals - see text.) 
Relative Volumetric Soil Water Content (\%)

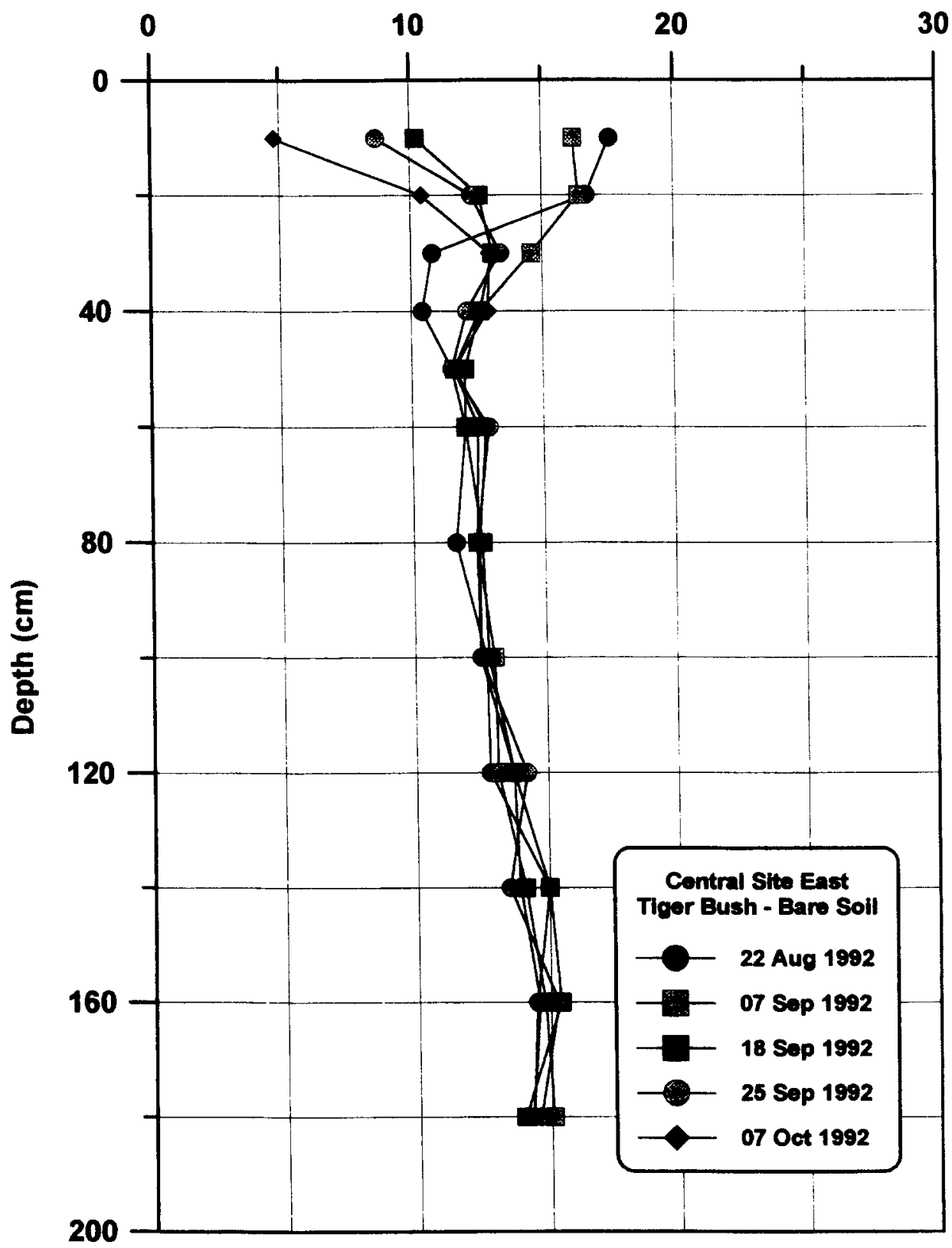

Fig. 15. Profile soil water content for Central Site East, tiger bush vegetation cover, bare soil conditions (Absolute values are uncertain due to the presence of iron minerals - see text.) 


\section{Relative Volumetric Soil Water Content (\%)}

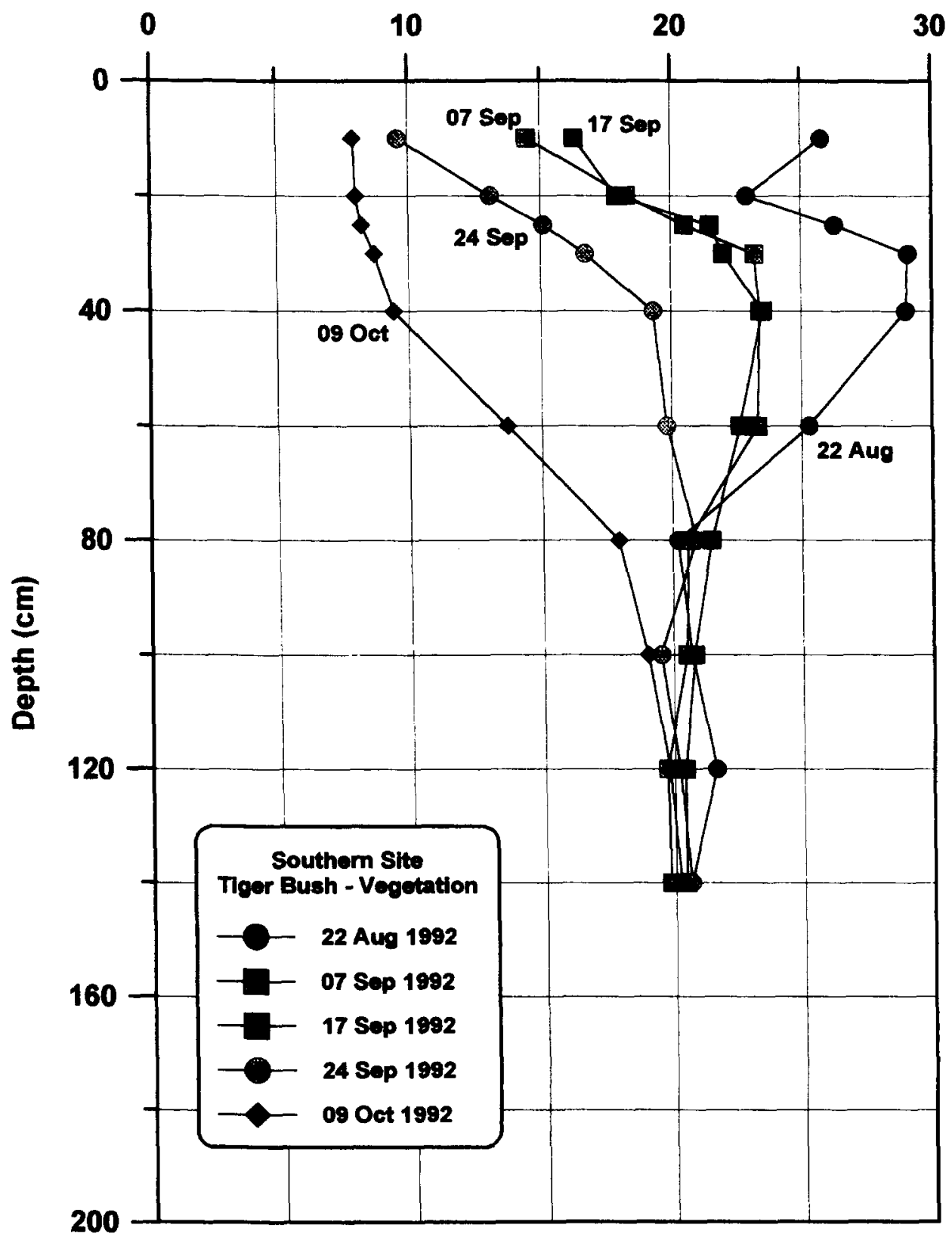

Fig. 16. Profile soil water content for Southern Site, tiger bush vegetation cover, vegetation strip. (Absolute values are uncertain due to the presence of iron minerals - see text.) 
Relative Volumetric Soil Water Content (\%)

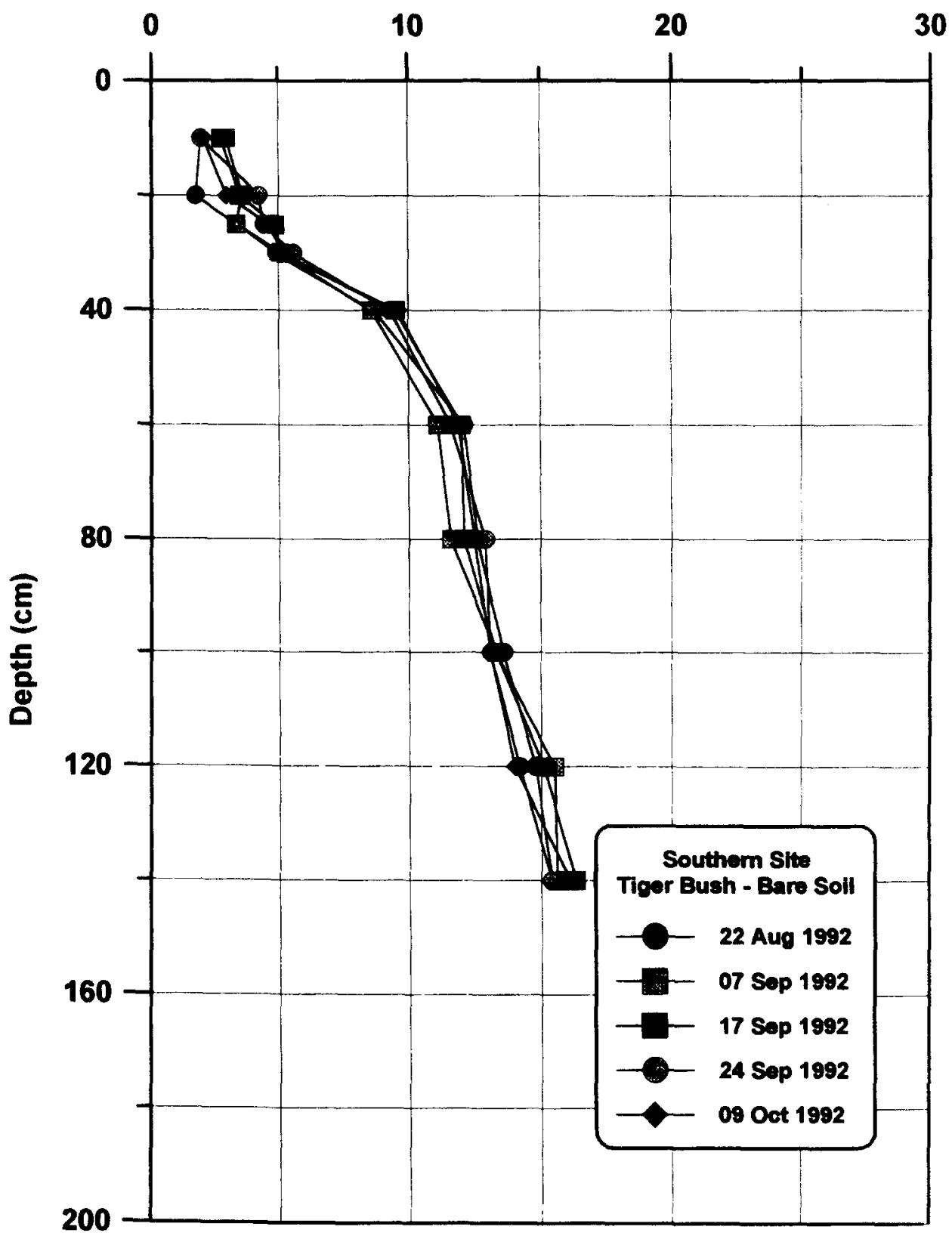

Fig. 17. Profile soil water content for Southern Site, tiger bush vegetation cover, bare soil conditions. (Absolute values are uncertain due to the presence of iron minerals - see text.) 
time are quite marked down to about $100 \mathrm{~cm}$ depth. That changes below $100 \mathrm{~cm}$ are much smaller does not mean that there is no extraction of water by the vegetation below that depth. Some of the shrub species in the tiger bush remain green for up to 5 or 6 months after the end of the rainy season. The volume of water that can be stored in the top $100 \mathrm{~cm}$ of the soil is not enough to meet transpiration demands for that time period. The plants must be extracting water from within and below the laterite layer which starts at about $100 \mathrm{~cm}$. The laterite layer is far from homogeneous. It is full of channels and clay pipes which can conduct water and roots. However, since the combined pore volumes of these conduits are relatively small, there is little change in the gross volumetric water content of the laterite layer whether these pores are full or empty. Therefore, even though the laterite layer may be quite active hydrologically, neutron counts for that layer are relatively constant, as shown in Figs. 16 and 17. The same remarks concerning local variation in the hydrologic balance, energy balance, and localized advection indicated for the Central Site East tiger bush apply in interpretation of Figs. 16 and 17.

Figs. 18 and 19 indicate the total soil water and recorded precipitation for the tiger bush cover of the Central Site East and Southern Site, respectively. Changes in stored soil water for the vegetation section are shown to be on the order of ten times the magnitude of changes measured in the bare soil. As previously indicated, such a disparity in adjacent areas of the same WAB is conducive to development of localized advection. This figure also brings into sharp focus the question of a representative value for stored soil water and soil water content over the tiger bush WAB. One may be able to support a representative value of soil water content over the vegetated area and another value over the bare soil area, but an average value in the sense of a water balance calculation for the tiger bush WAB is meaningless.

\subsection{Surface soil water distribution}

Time domain reflectometry (TDR) (0 to $15 \mathrm{~cm}$ depth) and the Institute of Hydrology surface capacitance insertion probe (SCIP) $(0$ to $5 \mathrm{~cm}$ depth) were used to evaluate soil water content in the surface layer. Tables 1-3 indicate the extent to which such measurements were made at each supersite. TDR and SCIP measurements were made both to study spatial variability of surface soil water content and in support of aircraft flying microwave sensors. The specific sampling method applied at each supersite is indicated in Tables 1-3.

Fig. 20 indicates the evolution with time of average surface soil water content from 0 to $15 \mathrm{~cm}$ measured by TDR over four vegetation covers at the Central Site East. The data shown cover approximately the first half of the IOP - the complete IOP extended from DOY 228 to 283 . Each point represents the mean of between 14 and 99 measurements for the particular vegetation cover and date. The maximum number of days monitored for the time period shown in the figure was 19 in the fallow, and the minimum was 6 in the milletsandy skirt. Data from individual days have been connected by straight lines to aid in visualizing the evolution of surface soil water, but there is no meaningful significance of the lines for days on which no data were taken.

In general, the fallow site tends to be the wettest of the four vegetation covers for the period shown and the millet-sandy skirt the driest. These sites also had the greatest and least amplitude, respectively, of surface soil water content. There are general wetting 
(uw) uo!̣eỵd!̣oad

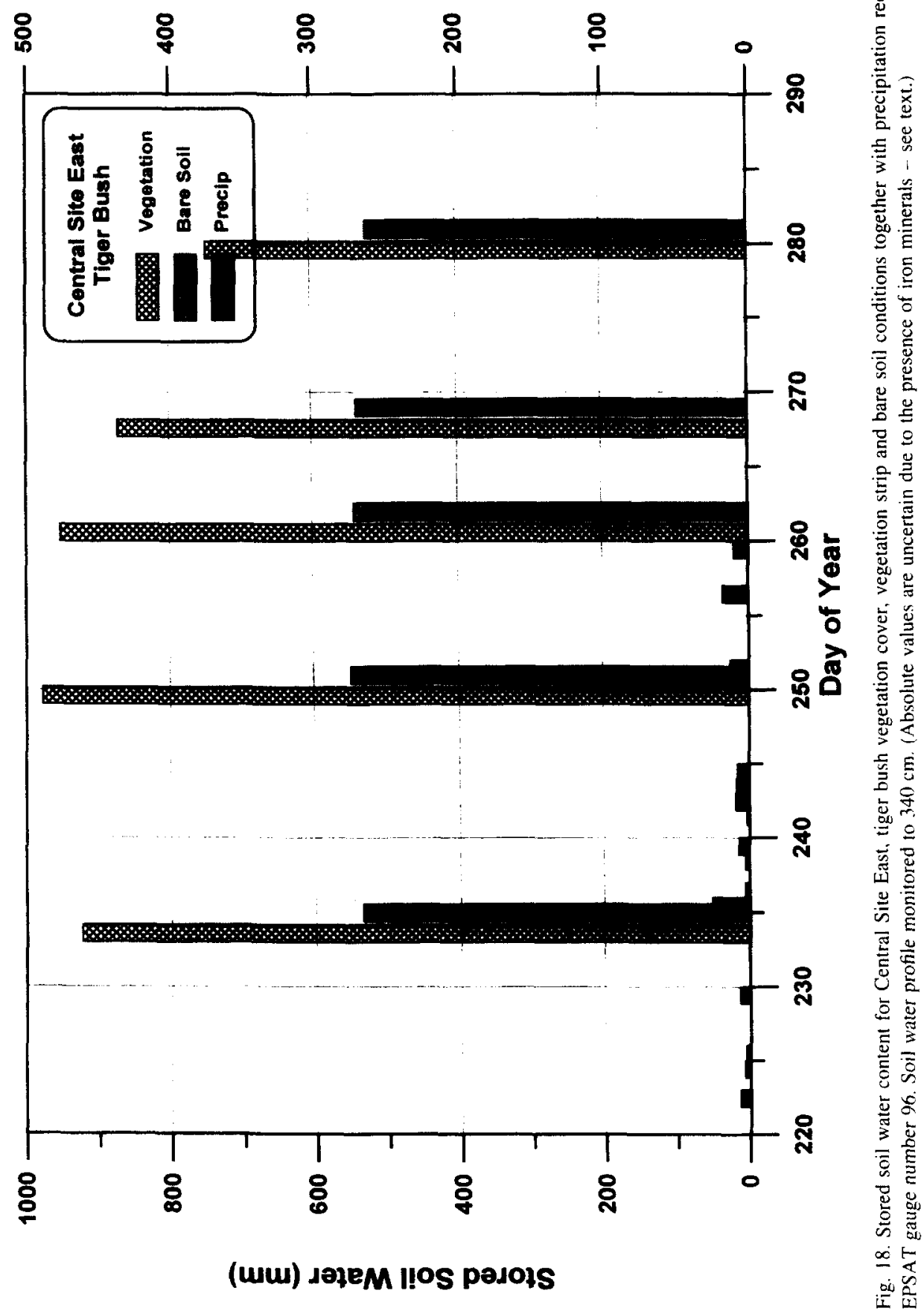




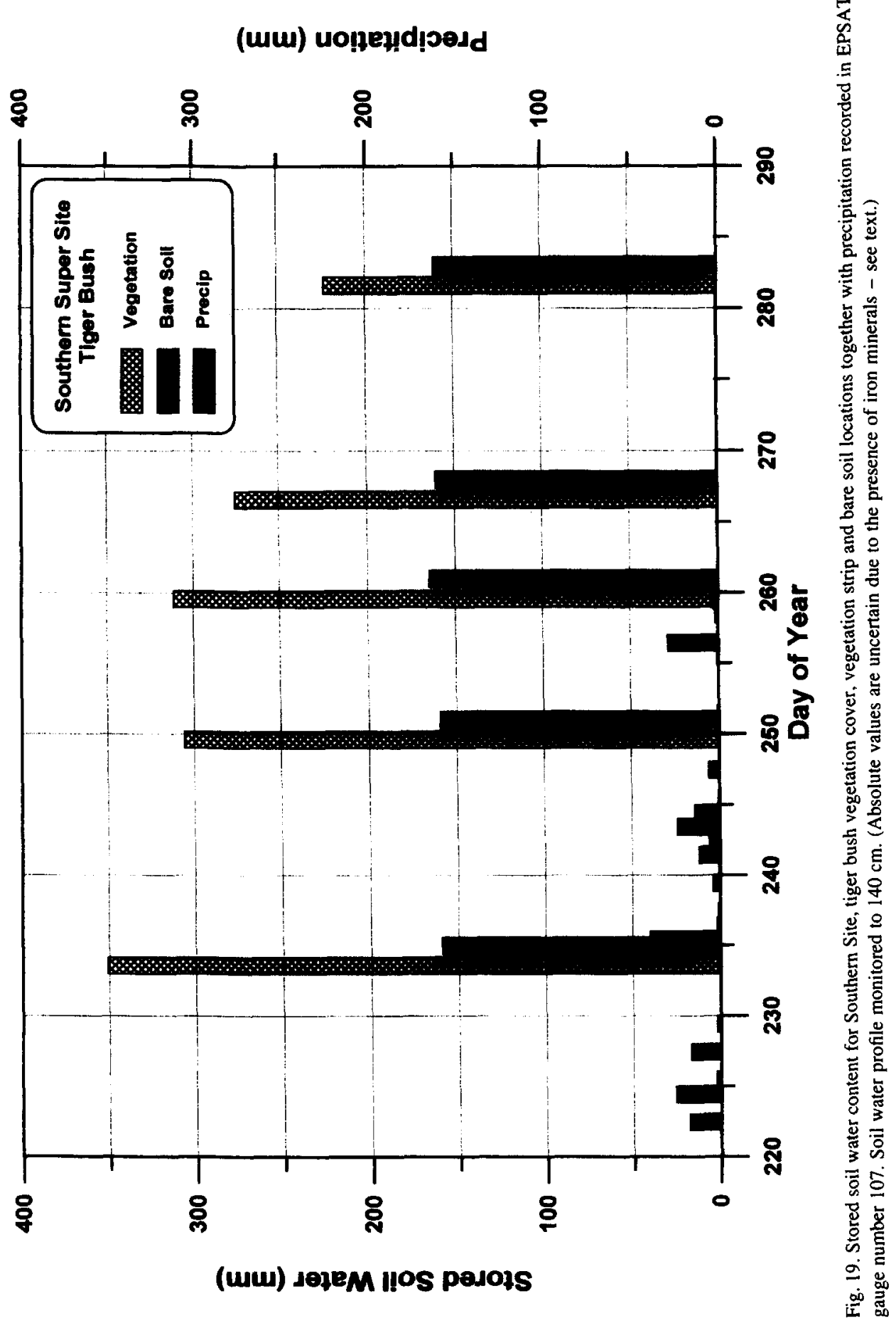


patterns from DOY 237 to 242,250 to 252 , and 254 to 259 . Drying patterns are evident from 242 to 250,252 to 254 , and 259 to 263 .

Fig. 21 indicates surface soil water content values measured by the surface capacitance probe from 0 to $5 \mathrm{~cm}$ for two vegetation covers in the Southern Site. Each point represents a mean of generally 50 measurements within the same vegetation cover. The recorded precipitation from the nearest EPSAT gauge is also plotted as a time series. The data extend nearly over the complete IOP. The 'negative soil water values' recorded by the capacitance probe discussed earlier have been zeroed for plotting purposes. Both sites show wide variation in amplitude in response to rainfall and soil drying conditions throughout the IOP. All of the surface soil water content data will be compared and correlated with the precipitation network data and the data taken from the NASA C-130 $\mathrm{L}$ band microwave radiometer and ARAT Fokker 27 PORTOS system. A detailed explanation of the procedures used in HAPEX-Sahel to calibrate remote sensing systems for soil moisture based on the ground-based data discussed above is given in Chanzy et al. (1997).

\subsection{Infiltration data}

Figs. 22 and 23 indicate results of tests made with the TRIMS tension infiltrometer system on two sites of the Central Site East with different types of soil crusts. This device allows for infiltration to proceed at a head of less than atmospheric pressure maintained on

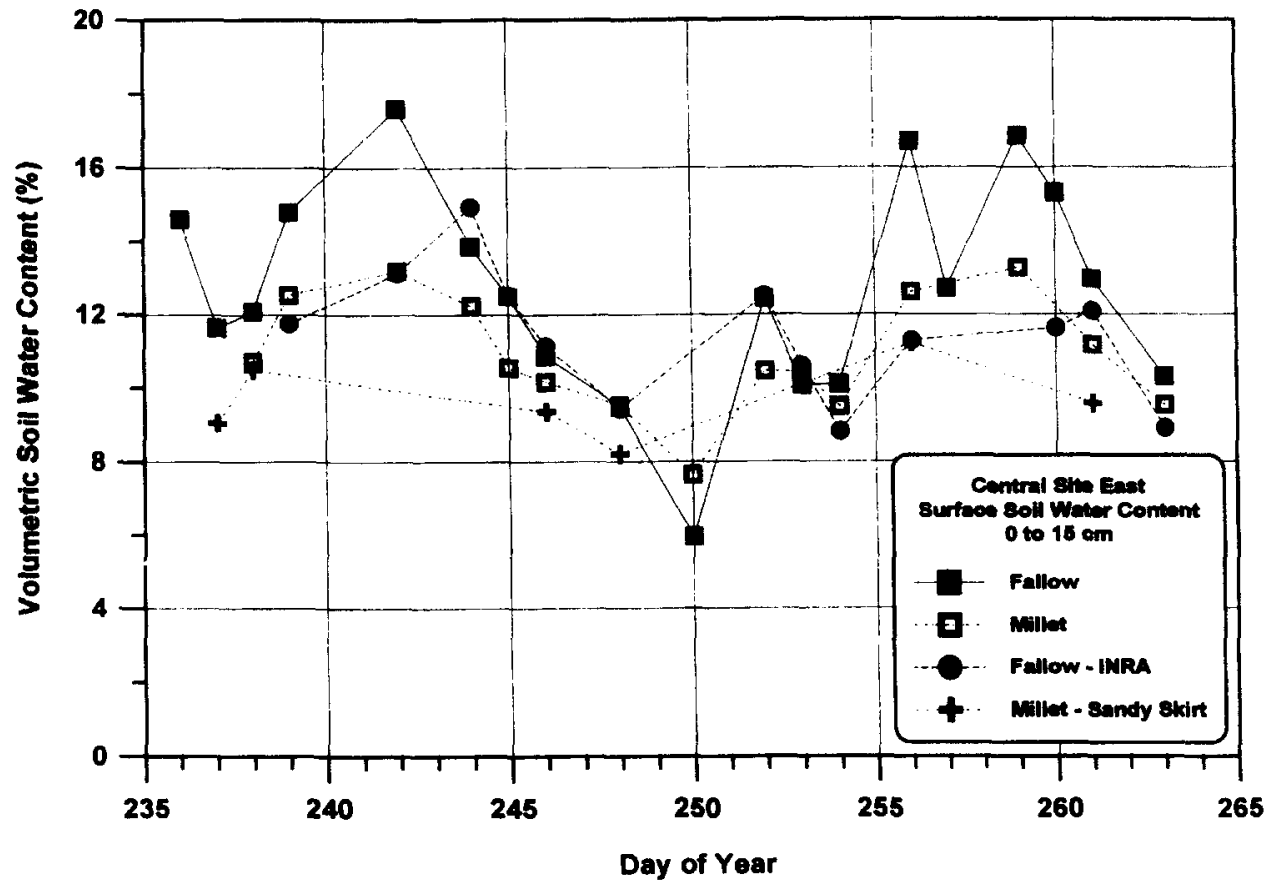

Fig. 20. Evolution of surface soil water content measured by TDR at Central Site East for four locations. 
(uiu) uolgey!d!oodd

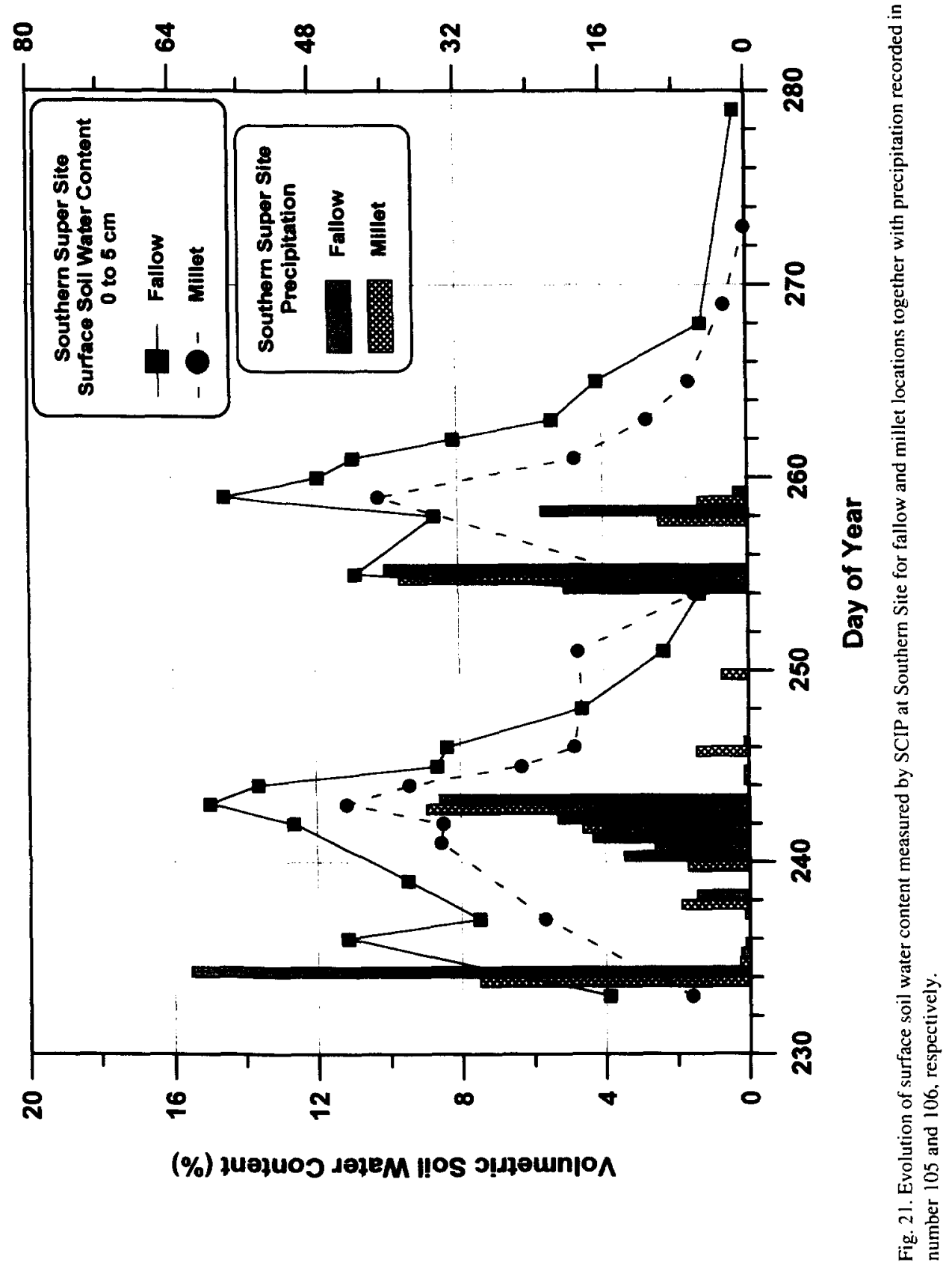


a membrane in contact with the soil surface (Jarvis et al., 1987; Perroux and White, 1988; Ankeny et al., 1991; Vauclin and Chopart, 1992). The results are shown for the S1 disk which has a diameter of $250 \mathrm{~mm}$ at the base. Each figure shows the equivalent depth of water infiltrated as a function of time. The slope of a line placed through the data is equivalent to the infiltration rate. Data corresponding to different tensions applied at the interface between the base of the disk and soil surface are indicated by different symbols.

Fig. 22 is for a sandy soil with an erosion crust, following the classification of Valentin and Bresson (1992). The infiltration rate exhibits a characteristic decrease with time for the first tension plotted $\left(100 \mathrm{~mm} \mathrm{H}_{2} \mathrm{O}\right.$ ) with the other tensions reaching a stable rate after a short initial period of adjustment. The curvilinear portion of the intake data (i.e. initially for $100 \mathrm{~mm}$ tension) is assumed to exhibit the effects of sorptivity phenomena while the linear portions of the plot represent control by hydraulic conductivity. Fluctuations shown in the first reading for any newly imposed tension are probably the result of the process of adjusting the tension, which often meant removing the infiltrometer momentarily from the soil surface. These initial points may therefore be disregarded and the more stable data which follow any adjustment should be considered the governing infiltration rate for any tension.

Fig. 23 demonstrates the same type of data, also taken with disk S1, for a sandy soil with an algal crust. The effects of change in tension are shown by an increase in the slope of the depth versus time line for a decrease in tension. A gradual decrease in the infiltration rate is shown for the initial tension of $100 \mathrm{~mm}$, while for the other tensions the reading stabilizes

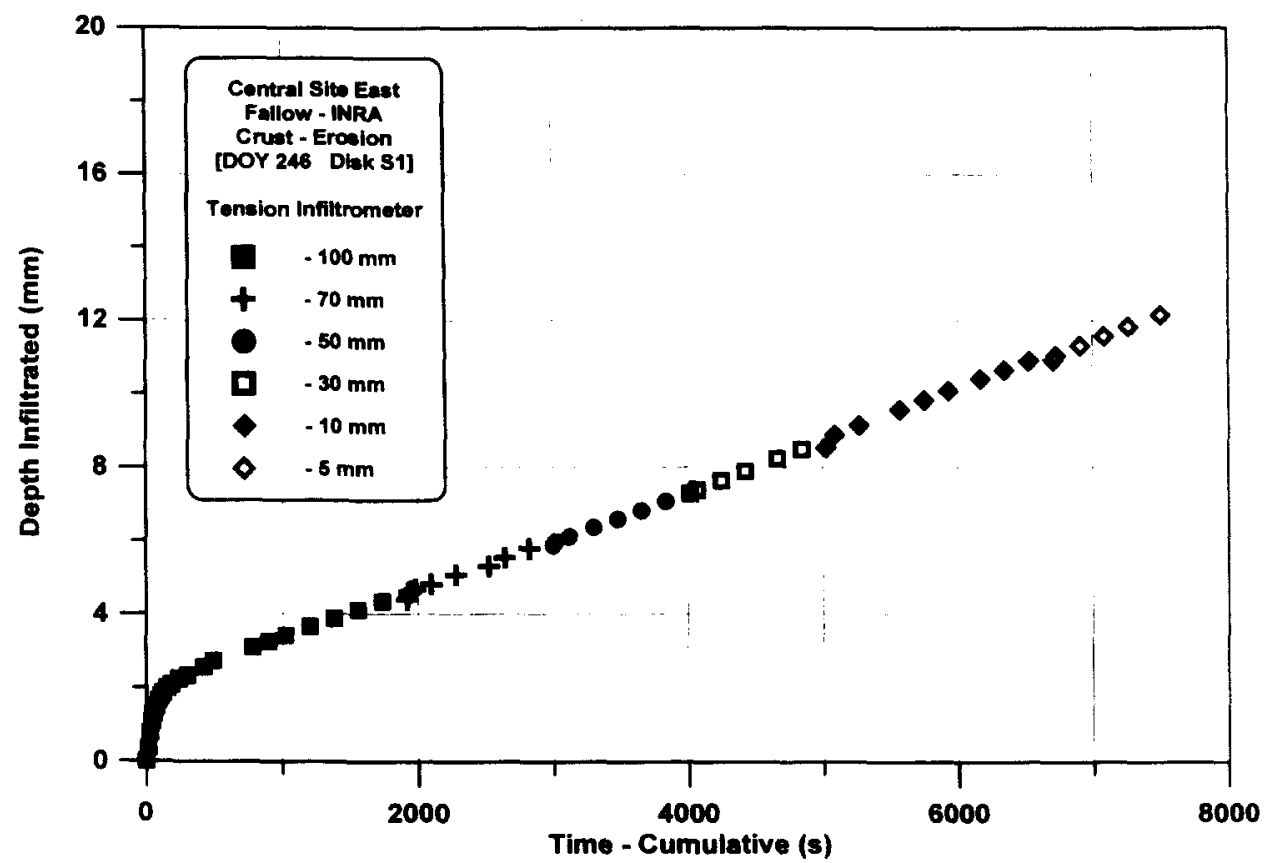

Fig. 22. Depth of infiltration as function of time for fallow vegetation cover (INRA) with erosion crust, Central Site East, for disk $\mathrm{Sl}$ of tension infiltrometer at various tensions. 
relatively quickly. The initial fluctuations in the data are due to the same cause as described for Fig. 22. It is clear from the increasing slope that the infiltration rate is stabilizing at a higher rate as the tension is decreased. This is presumably due to the transmission of water by larger soil pores which become filled as the tension decreases. Such a phenomenon is not demonstrated in the erosion crust plot. The infiltration rates exhibited by the erosion crust site are approximately an order of magnitude lower than those shown for the algal crust. The two crusts will therefore generate significantly different amounts of runoff for precipitation events of similar intensity. The infiltration rate analysis is an essential element in comprehending the redistribution of precipitation in the Sahel environment. The ultimate objective of the TRIMS data set will be to define the unsaturated hydraulic conductivity of both the crust and underlying soil as a function of tension for those cases in which the assumptions of the method applied are valid. Additional information on the tension infiltrometer technique applied and results from the HAPEX-Sahel experiment are given in Vandervaere et al. (1997).

\section{Summary}

The HAPEX-Sahel experiment brought together researchers from the fields of hydrology, ecology, soil science, biological science, atmospheric science, and remote sensing. It was conducted on a regional scale of $100 \mathrm{~km}$ by $100 \mathrm{~km}$ which contained

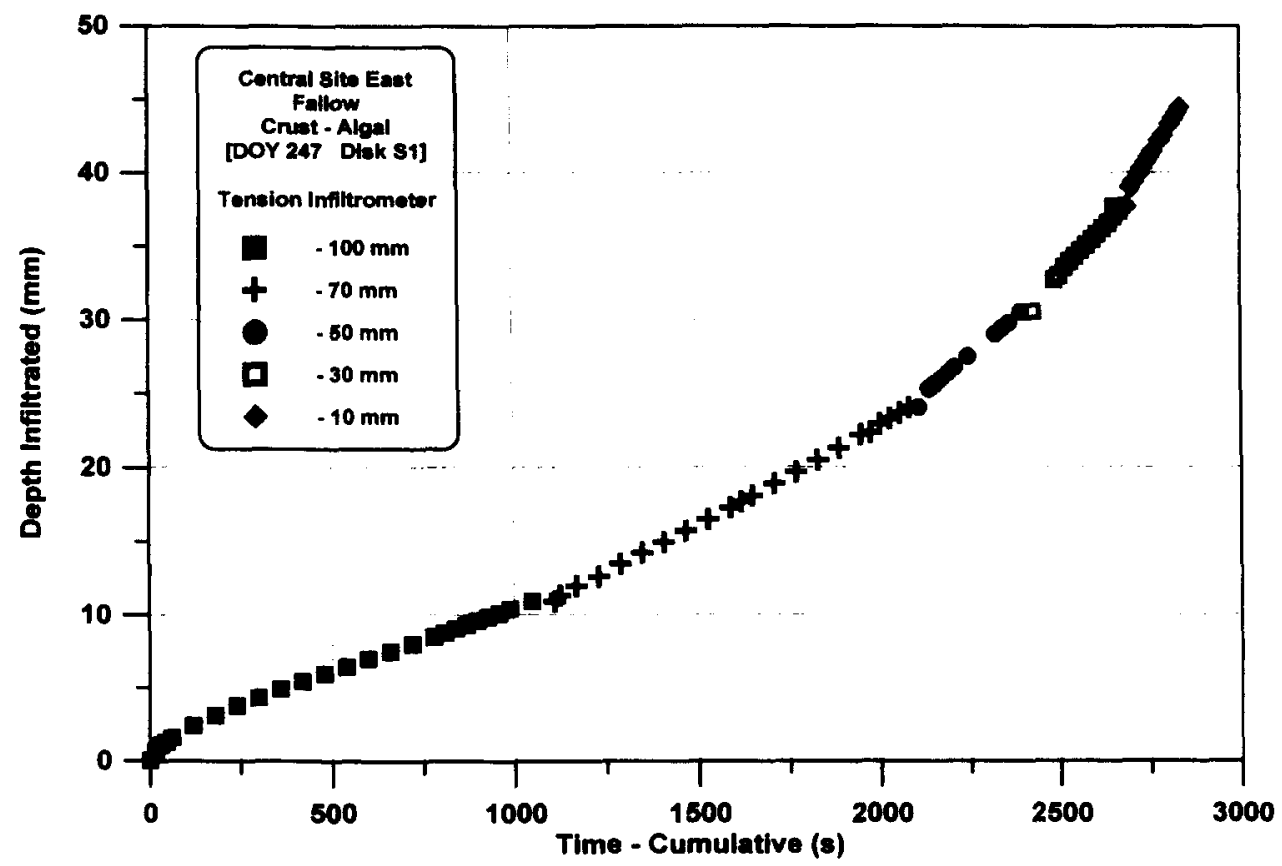

Fig. 23. Depth of infiltration as function of time for fallow vegetation cover with algal crust, Central Site East, for disk SI of tension infiltrometer at various tensions. 
three supersites. Within each supersite three to four vegetation types were monitored. The soils component was incorporated as an integral part of the project and involved measurement of soil physical processes and monitoring of soil water content and soil water potential. The results of this aspect of the project will be applied to the development and improvement of simulation models in soil physics, calibration of remote sensing systems, and initialization and verification of simulation models for surface energy balance and atmospheric processes.

Detailed descriptions of the soil-related measurements made at each supersite for each vegetation cover are given. Measurement instrumentation included neutron probe, time domain reflectometry, surface capacitance probe, tensiometer, tension infiltrometer, and soil core sampling. In some cases, standard calibration techniques could be applied, while in others the unique soil environment of the experimental area required special techniques.

The profile soil water data indicate patterns which are typical of surface evaporation and root extraction towards the upper part of the profile with gradual drainage towards the bottom, but at consistently lower levels of soil water than encountered in previous regional experiments. The consistent relationship between wet and dry sites within the same WAB supports the notion of consistency of wet and dry locations throughout a season. The temporal distribution of rainfall throughout the IOP is clearly demonstrated in the profile data. An interactive layer of only the top 30 to $50 \mathrm{~cm}$ in the bare soil of the tiger bush is in sharp contrast with the penetration to more than $3 \mathrm{~m}$ depth of the infiltration front in the vegetative portion.

The stored soil water data demonstrate the effects of spatial variability of rainfall over the experimental domain. The time distribution of maximum and minimum stored quantities indicates that the overall objective of capturing the greatest changes in evaporative flux during the IOP was very nearly realized. The data from both tiger bush sites demonstrate that variation of soil water in the vegetation area was on the order of ten times greater than variation in the bare soil section. This variation is due to the fact that the infiltration capacity of the bare soil strips is virtually nil. The resulting difference in evaporative fluxes indicates the strong potential for development of local advective conditions within the tiger bush WABs.

Surface soil water content was measured using TDR and capacitance probes. Sample data indicate the general response of this parameter to rainfall distribution. The generally large number of samples of surface data for a given vegetation cover will be applied to studies of soil water variability and coupled with the remote sensing data set for parameterization of surface soil water, particularly for the microwave radiometer. Tension infiltrometer data from all three supersites indicate the controlling role played by surface crust conditions in the Sahelian environment. Tension infiltrometer data from the TRIMS system using different radii bases at different tensions will be used to determine the hydraulic conductivity function for different soil textures in the experimental domain.

\section{Acknowledgements}

Numerous individuals and agencies contributed to the success of those aspects of HAPEX-Sahel described in this overview. Diafarou Amadou, Idé Sanda, Djibo Soumaila, and Zurkafili Amadou collected much of the neutron probe data at the Southern Supersite. 
The Director of the ICRISAT Sahelian Center provided use of the Center's facilities during the HAPEX-Sahel campaign. The groups from Wageningen Agricultural University and the Institute of Hydrology were supported by concurrent research grants from the European Community. Team members from the Laboratoire d'Etude des Transferts en Hydrologie et Environnement (LTHE) were supported by the Centre National de la Recherche Scientifique (CNRS) Programme Environnement and PAMOS. The sabbatical leave of R.H. Cuenca who was attached to LTHE was supported by CNRS and Oregon State University. Major support for deployment of the ARAT system, remote sensing data analysis and development and maintenance of the HAPEX-Sahel Information System (HSIS) was provided by the Centre National d'Etudes Spatiales (CNES). This article was coordinated by R.H. Cuenca and J. Brouwer, who alternated in chairing the HAPEX-Sahel soil water group. Contributions from various institutes were coordinated by A. Chanzy, P. Droogers. S. Galle, S.R. Gaze, M. Sicot, H. Stricker, J.D. Cooper, and M. Soet. D. Stangel and S. Kelly of Oregon State University assisted in preparation of the graphics and the final version of the manuscript.

\section{References}

André, J.C., Goutorbe, J.P., Perrier, A., Becker, F., Bessemoulin, P., Bougeault, P., Brunet, Y., Brutsaert, W., Carlson, T., Cuenca, R., Gash, J., Gelpe, J., Hilderbrand, P., Lagouarde, J.P., Lloyd, C., Mahrt, L., Mascart, P., Mazaudier, C., Noilhan, J., Ottlé, C., Payan, M., Phulpin, T., Stull, R., Shuttleworth, J., Schmugge, T., Taconet, O., Tarrieu, C., Thepenier, R.M., Valancogne, C., Vidal-Madjar, D. and Weill, A., 1988. Evaporation over land-surfaces. First results from HAPEX-MOBILHY Special Observing Period. Ann. Geophys., 6: 477-492.

Ankeny, M.D., Ahmed, M., Kaspar, T.C. and Horton, R., 1991. Simple field method for determining unsaturated hydraulic conductivity. Soil Sci. Soc. Am. J., 55: 467-470.

Bell, J.P., 1987. Neutron Probe Practice. Institute of Hydrology Report No. 19, 3rd edn., Wallingford, UK.

Bertuzzi, P., Bruckler, L., Gabilly, Y. and Gaudu, J.C., 1987. Calibration and error analysis of a gamma ray probe for in situ measurement of dry bulk density. Soil Sci., 144(6): 425-436.

Boiffin, J. and Monnier, G., 1985. Infiltration rate as affected by soil surface crusting caused by rainfall. In: F. Callebaut, D. Gabriels and M. De Boodt (Editors), Assessment of Soil Surface Crusting, Proceedings Symposium ISS AISS IBG, Ghent, Belgium. pp. 210-217.

Bolle, H.J., Andre, J.-C., Amue, J.L., Barth, H.K., Bessemoulin, P., Brasa, A., de Bruin, H.A.R., Cruces, J., Dugdale, G., Engman, E.T., Evans, D.L., Fantechi, R., Fiedler, F., van de'Griend, A., Imeson, A.C., Jochum, A., Kabat, P., Kratzsch, T., Lagouarde, J.-P., Langer, I., Llamas, R., Lopez-Baeza, E., Melia Miralles, J., Muniosguren, L.S., Nerry, F., Noilhan, J., Oliver, H.R., Roth, R., Saatchi, S.S., Sanchez Diaz, S., de Santa Olalla, M., Shuttleworth, W.J., Søgaard, H., Stricker, H., Thornes, J., Vauclin, M. and Wickland, D., 1993. EFEDA: European Field Experiment in a Desertification-threatened Area. Ann. Geophys., 11(2/3): 173-189.

Casenave, A. and Valentin, C., 1989. Les États de Surface de la Zone Sahélienne. Influence sur l'infiltration. ORSTOM, Collection "Didactiques", 230 pp.

Chanzy, A., Schmugge, T.J., Calvet, J.-C., Kerr, Y., Van Oevelen, P., Grosjean, O. and Wang, J.R., 1997. Airborne microwave radiometery on a semi-arid area during HAPEX-Sahel. J. Hydrol., this issue.

Clausnitzer, V., Hopmans, J.W. and Nielsen, D.R., 1992. Simultaneous scaling of soil water retention and hydraulic conductivity curves. Water Resour. Res., 28(1): 19-32.

Couchat, P., Carre, C., Marcesse, J. and Ho, J., 1975. The measurement of thermal neutron constants of the soil: application to the calibration of neutron moisture gauges and to the pedological study of the soil. In: R.A. Schrack and C.D. Bowman (Editors), Nuclear Cross-Sections and Technology. US Department of Congress, pp. 516-579. 
Cuenca, R.H., 1988. Hydrologic balance model using neutron probe data. Am. Soc. Civ. Eng., J. Irrig. Drain. Eng., 114(4): 644-663.

Cuenca, R.H., 1989. Irrigation System Design - An Engineering Approach. Prentice-Hall, Inc., Englewood Cliffs, NJ, $552 \mathrm{pp}$.

Cuenca, R.H. and Noilhan, J., 1991. Use of soil moisture measurements in hydrologic balance studies. In: T.J. Schmugge and J.C. André (Editors), Land Surface Evaporation - Measurement and Parameterization. Springer-Verlag, New York, pp. 287-299.

Dean, T.J., Bell, J.P. and Baty, A.J.B., 1987. Soil moisture measurement by an improved capacitance technique, Part 1. Sensor design and performance. J. Hydrol., 93: 67-78.

Gaze, S.R., Simmonds, L.P., Brouwer, J., and Bouma, J., 1997. Measurement of surface redistribution of rainfall and modelling its effects on water balance calculations for a millet field on sandy soil in Niger. J. Hydrol., this issue.

Goutorbe, J.P., Noilhan, J., Valancogne, C. and Cuenca, R.H., 1989. Soil moisture variations during HAPEXMOBILHY. Ann. Geophys., 7(4): 415-426.

Goutorbe, J.-P., Lebel, T., Tinga, A., Bessemoulin, P., Brouwer, J., Dolman, A.J., Engman, E.T., Gash, J.H.C., Hoepffner, M., Kabat, P., Kerr, Y.H., Monteny, B., Prince, S., Said, F., Sellers, P. and Wallace, J.S., 1994. HAPEX-Sahel: a large scale study of land-atmosphere interactions in the semi-arid tropics. Ann. Geophys., 12: 53-64.

Grant, D.R., 1975. Measurement of soil moisture near the surface using a neutron moisture meter. J. Soil Sci., 26: 124-129.

Grime, V.L., 1992. Thermal methods for measuring sap flow through intact plant stems: an evaluation of methods and their application for determining the factors controlling transpiration in a stand of heterogeneous natural vegetation: a case study for Guiera senegalensis, the dominant woody shrub species in the fallow savanna of Niger. Ph.D. Thesis. Departments of Soil Science and Meteorology, University of Reading, UK.

Haverkamp, R., Vauclin, M. and Vachaud, G., 1984. Error analysis in estimating soil water content from neutron probe measurements: 1. local standpoint. Soil Sci., 137(2): 78-90.

Heimovaara, T.J. and Bouten, W., 1990. A computer controlled 36 channel Time Domain Reflectometry system for monitoring soil water contents. Water Resour. Res., 26: 2311-2316.

Hillel, D., 1982. Introduction to Soil Physics. Academic Press, New York, 364 pp.

Hopmans, J.W. and Stricker, J.N.M., 1989. Stochastic analysis of soil water regime in a watershed. J. Hydrol., 105: 57-84.

Jarvis, N.J., Leeds-Harrison, P.B. and Dosser, J.M., 1987. The use of tension infiltrometers to assess routes and rates of infiltration in a clay soil. J. Soil Sci., 38: 641-649.

Mullins, C.E., 1991. Matric potential. In: K.J. Smith and C.E. Mullins (Editors), Soil Analysis - Physical Methods. Marcel Dekker, New York, pp. 75- 109.

Nichols, W.E., Cuenca, R.H., Schmugge, T.J. and Wang, J.R., 1993. Pushbroom microwave radiometer results from HAPEX-MOBILHY. Remote Sensing Environ., 46: 119-128.

Nielsen, D.R., Biggar, J.W. and Erh, K.T., 1973. Spatial variability of field-measured soil-water properties. Hilgardia, 42: 215-260.

Parkes, M.E. and Siam, N., 1979. Error associated with measurement of soil moisture change by neutron probe. J. Agric. Eng. Res., 24: 87-93.

Perroux, K.M. and White, 1., 1988. Designs for disc permeameters. Soil Sci. Soc. Am. J., 52: 1205-1215.

Reynolds, W.D. and Elrick, D.E., 1985. In situ measurements of field-saturated hydraulic conductivity, sorptivity and the $\alpha$-parameter using the Guelph permeameter. Soil Sci., 133:61-64.

Reynolds, W.D. and Elrick, D.E., 1991. Determination of hydraulic conductivity using a tension infiltrometer. Soil Sci. Soc. Am. J., 55: 633-639.

Robinson, M. and Dean, T.J., 1993. Measurement of near surface soil water content using a capacitance probe. Hydrol. Proc., 7: 77-86.

Roth, K., Schulin, R., Fluhler, H. and Attinger, W., 1990. Calibration of Time Domain Reflectometry for water content measurement using a composite dielectric approach. Water Resour. Res., 26: 2267-2273.

Schmugge, T.J. and Becker, F., 1991. Remote sensing observations for the monitoring of land-surface fluxes and water budgets. In: T.J. Schmugge and J.C. André (Editors), Land Surface Evaporation - Measurement and Parameterization. Springer-Verlag, New York, pp. 337-347. 
Sellers, P., Hall, F.G., Asrar, G., Strebel, D.E. and Murphy, R.E., 1992. An overview of the First International Satellite Land Surface Climatology Project (ISLSCP) Field Experiment (FIFE). J. Geophys. Res., 97(DI7): $18345-18373$.

Sellers, P., Hall, F.G., Margolis, H., Kelly, B., Baldocchi, D., den Hartog, J., Cihlar, J., Ryan, M., Goodison, B., Crill, P., Ranson, J., Lettenmaier, D. and Wickland, D., 1995. The Boreal Ecosystem-Atmospheric Study (BOREAS): an overview and early results from the 1994 field year. Bull. Am. Meteorol. Soc., 76(9): 15491577.

Simmons, C.S., Nielsen, D.R. and Biggar, J.W., 1979. Scaling of field-measured soil-water properties. Hilgardia, 47: $77-174$.

Taupin, J.-D., Lebel, T., Cazenave, F., Gread, M., Kong, J., Lecocq, J., Adamson, M., d'Amato, N. and Ben Mohamed, A., 1993. EPSAT-Niger Campagne 1992. ORSTOM, DMN, 64 pp.

Taylor, S.A. and Ashcroft, G.L., 1972. Physical Edaphology. W.H. Freeman and Co., San Francisco, CA, 533 pp.

Thony, J.-L., Vachaud, G., Clothier, B.E. and Angulo-Jaramillo, R., 1991. Field measurement of the hydraulic properties of soil. Soil Tech., 4: 111-123.

Topp, G.C., Davis, J.L. and Annan, A.P., 1980. Electromagnetic determination of soil water content: measurements in coaxial transmission lines. Water Resour. Res., 16: 574-582.

Vachaud, G., Passerat de Silans, A., Balabanis, P. and Vauclin, M., 1985. Temporal stability of spatially measured soil water probability density function. Soil Sci. Soc. Am. J., 49: 822-828.

Valentin, C. and Bresson, L.-M., 1992. Morphology, genesis and classification of surface crusts in loamy and sandy soils. Geoderma, 55: 225-245.

Vandervaere, J.-P., Vauclin, M., Haverkamp, R. and Cuenca, R.H., 1994a. Error analysis in estimating soil water balance of irrigated fields during the EFEDA experiment: 1. local standpoint. J. Hydrol., 156: 351-370.

Vandervaere, J.-P., Vauclin, M., Haverkamp. R. and Cuenca, R.H., 1994b. Error analysis in estimating soil water balance of irrigated fields during the EFEDA experiment: 2. Spatial standpoint. J. Hydrol., 156: 371-388.

Vandervaere, J.-P., Peugeot, C., Vauclin, M., Angulo Jaramillo, R. and Lebel, T., 1997. Estimating hydraulic conductivity of crusted soils using disc infiltrometers and minitensiometers. J. Hydrol., this issue.

Vauclin, M. and Chopart, J.-L., 1992. L'infiltrométrie multidisques pour la détermination in situ des caractéristiques hydronamiques de la surface d'un sol gravillonnaire du Côte d'Ivoire. Agron. Trop., 46(4): 259271.

Vauclin, M. and Vachaud, G., 1981. Bilan hydrique dans le Sud Tunisien, 2, Modélisation numérique et prévision des transferts hydriques en sol stratifié. J. Hydrol., 49: 53-73.

Vauclin, M., Haverkamp, R. and Vachaud, G., 1984. Error analysis in estimating soil water content from neutron probe measurements: 2. Spatial standpoint. Soil Sci., 137: 14I-148.

Warrick, A.W., 1990. Application of scaling to the characterization of spatial variability in soils. In: D. Hillel and D.E. Elrick (Editors), Scaling in Soil Physics - Principles and Applications. Soil Science Society of America Special Publication No. 25, Madison, WI, pp. 39-51. 